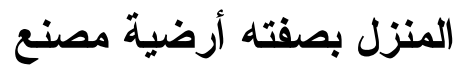

\section{توظيف وتعويضات}

\section{العاملين من المنازل}

\section{وندي كننغهام وكارلوس راموس غوميز \\ البنك الدولي}

بعرف العدل من الهنازل (أو العمل المنزلي) على أنه عمل موجه للسوق بقوم به أثخاص من غير الدهنيين

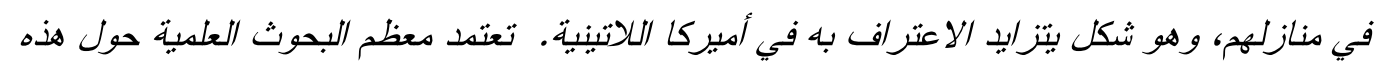

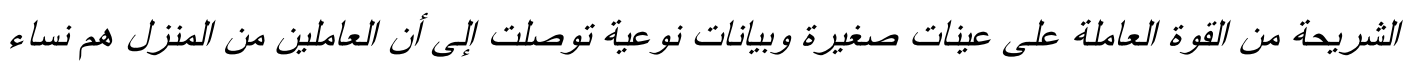

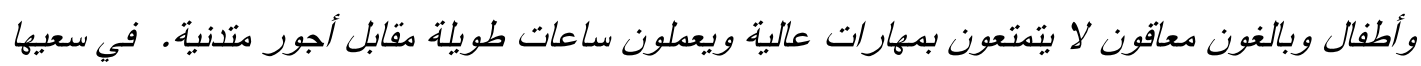

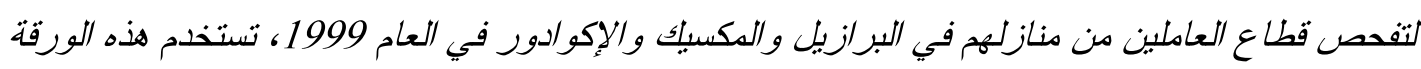

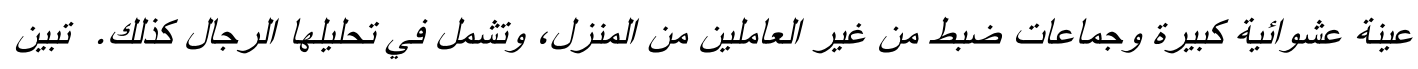

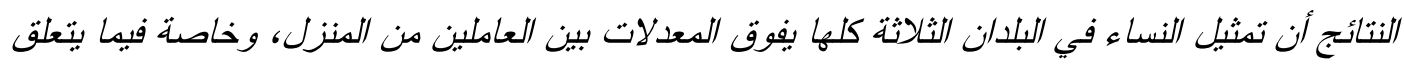

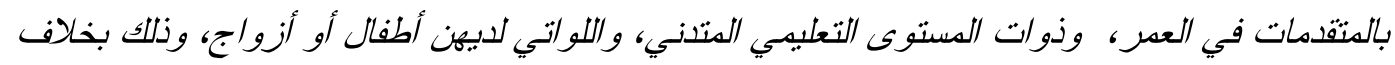

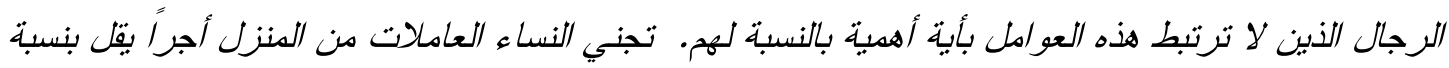

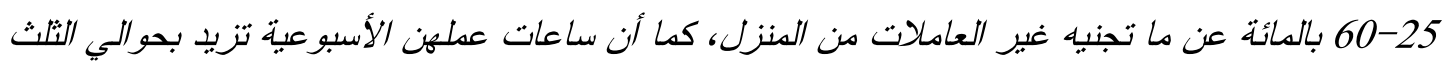

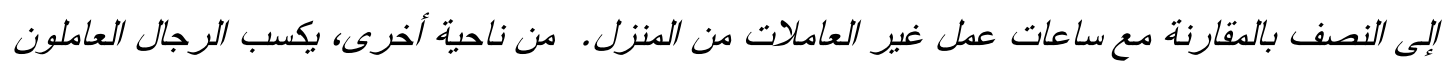

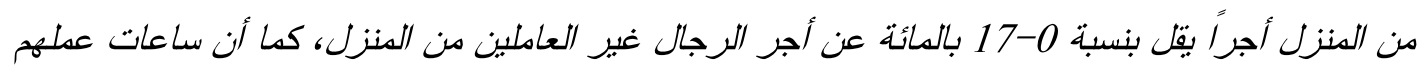

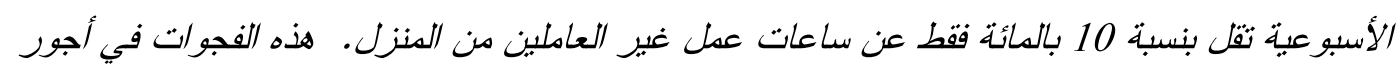

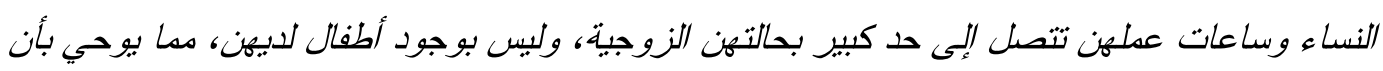

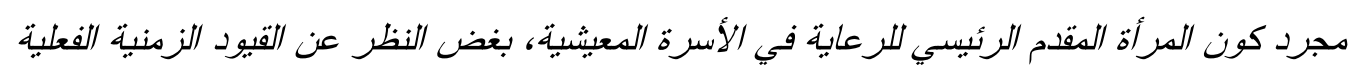

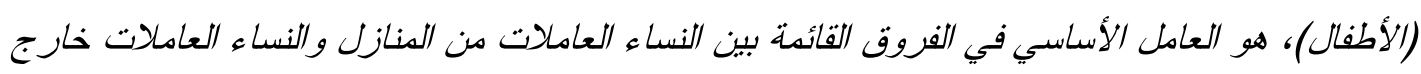

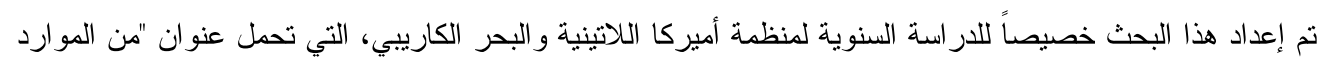

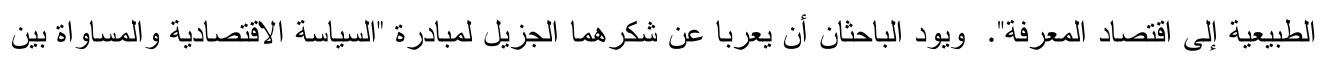

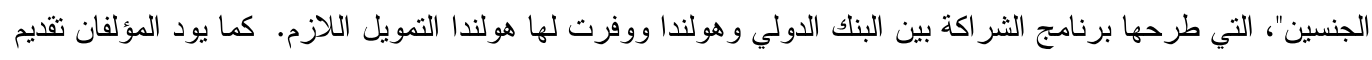

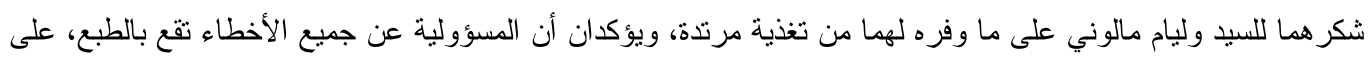




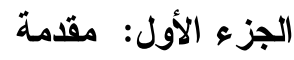

لقد حظي العمل من المنزل مؤخراً باهتمام متز ايد، وخصوصاً في سياق العولمة. وفي هذا الصدد، يحاول أحد اتجاهات الأدبيات المتاحة إقامة الدليل على أن الشركات المتتافسة من أجل البقاء في الاقتصاد العالمي تبحث عن أساليب إنتاجية تعمل على تعظيم المرونة من حيث الجداول الزمنية للإنتاج ومدخلات عو امله، وتولد، في الوقت نفسه، مخرجات نوعية بأسعار نتافسية على الساحة الدولية. هذا يتطلب إعادة تنظيم عمليات الإنتاج بحيث أن عمليات التجميع النهائي و التغليف و إدخال البيانات، و غير ذلك من المهام التي لا تتطلب مستويات عالية من المهار ات، تتم بصورة متتاقصة في المصانع وبصورة متز ايدة في المنازل، وذلك بموجب عقود مصانعة (كار 2000، ويغو 2000)². الجدير ذكره هنا أن غياب القوة العاملة الدائمة ور أس المال الثابت يسمح للشركات بأن تغير بسهولة أساليب الإنتاج، أو السلع التي تتنجها، أو مواقع الإنتاج، مما يسفر عن تخفيض التكاليف (منظمة العمل الدولية 1995، بروغل 1997، بينيريا ورولدون 1987). إضافة إلى ذلك، نجد أن جزءاً من القوة العاملة ممن يعانون من قيود تعيق التحاقهم بالعمل خارج المنزل ــ إما بسبب صعوبة الانتقال(ذوو الإعاقات) أو بسبب الو اجبات المنكررة الني ينبغي القيام بها طيلة النهار في المنزل (مقدمو الرعاية الأولية في الأسرة المعيشية) - يشكلون فيما بينهر مجموعة من العاملين المحتملين من منازلهم، مما يسهم في تخفيض الأجور وتقليص التكاليف على أصحاب العمل. ترد أدبيات أخرى على هذه الحجة قائلة إن العمل من المنزل يشكل تنظيماً مفضلاً للمشاركة في قوة العمل بالنسبة للعاملين الذين يو اجهون صعوبة في العمل خارج منازلهم، وأن العولمة هي التي تسهل هذا العمل، إلا أنها لا تعيقه (منظمة العمل الدولية 1995).

ليس من السهل البت في هذه المناقثة، إذ أنه لا يتوفر سوى القليل من الأدلة على الدو افع الكامنة وراء التوجه إلى العمل من المنزل أو طبيعة ذلك العمل. فمع أن خبر اء الاقتصاد يقرون بصورة متز ايدة بوجود تباين في القطاع غير الرسمي وبالحاجة إلى تحليل كل شريحة من شر ائحه على حدة، إلا أن در اساتهم لا تناقش قطاع

2 القد أسفرت إعادة تنظيم الإنتاج من أجل تخفيض التكاليف إلى حدها الأدنى على جميع مستويات الإنتاج عن تطوير ما أطلق

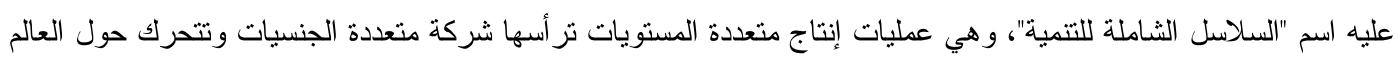

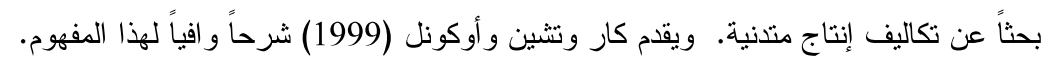


العمل من المنازل (كننغهام ومالوني 2001، مالوني، قيد النشر). يعزى هذا جزئياً إلى الافتقار إلى مجمو عات كبيرة من البيانات الخاصة بالعينات الإحصائية، و التي من شأنها أن تسمح بإجر اء التحليلات الاقتصادية (تشين 1999). بدلاً من ذلك، فإن غالبية الأدلة مستمدة من دراسات الحالة النوعية و البيانات المستقاة من المقابلات التي يجريها مع أفر اد عينات إحصائية صغيرة مختصون بعلم الاجتماع و علم الإنسان (تثين 1999؛ بروغل 1997؛ كار 2000). أما الصورة المحدة التي يعطيها هؤلاء الباحثون، فهي أن العمل المنزلي يقوم به في المقام الأول النساء و أطفالهن (تثين 1999)، الذين يؤدون مهام بسيطة ومتكررة ومكثفة للعمالة (أرياغادا 1998)، و على مدى ساعات طويلة وبأجور زهيدة. بما أن العمل يتم أداؤه في خلوة المنزل الخاص بالعامل، فإن العاملين يخضعون لظروف عمل سيئة ويتمتعون ببضع حمايات3 ويعانون من العزلة (ويغو 2000).

مع أن بعض هذه الاستتناجات مسلم بها، إلا أن استتناجات أخرى قد تستفيد من المزيد من التحليل على أساس عينة إحصائية عشو ائية كبيرة. فالو اضح أن تحليل البيانات المتعلقة بالعاملين من المنازل، إذا نم بالاشتر الك مع تحليل البيانات المتعلقة بمجموعة ضبط من عمال لهم نفس الخصائص، ولكنهم لا يعملون من منازلهم، سوف يكثف عما إذا كان العاملون من المنازل يتلقون أجوراً أقل ويعملون ساعات أطول بسبب قيود محددة يفرضها عليهح سوق العمل، أو ما إذا كانت أوضاعهر هي نفسها أوضاع غير العاملين من المنزل الذين يخضعون للقيود ذاتها.

تستخدم هذه الورقة در اسات المسح الأسري في كل من البرازيل و الإكو ادور و المكسيك لكي تختبر بطريقة تجريبية النتائج المستقاة من الأبحاث الإثثوغر افية التي تعتمد على عينات إحصائية صغيرة، وتتصدى في ذلك لثلاثة أسئلة أساسية: من هم العاملون من المنزل؟ هل يثقاضون أجوراً أقل من المعتاد؟ هل يعملون ساعات طويلة فوق العادة؟ أما عملية تحليل البيانات، فتلجأ إلى ثلاث مجموعات مقارنة من غير العاملين من المنزل وتحاول ضبط العينة وفق خصائص قد تكون مسؤولة عن الفروق التي تتم ملاحظتها في التحليل النوعي.

لقد استتت بلدان عديدة تشريعات تحكم عمل السوق الذي يتم أداوه في المنازل (منظمة العمل الدولية 1995)، لكن التبليغ عن مخالفة القو انين بعتبر منخفضاً. 
توجه الورقة اهتماماً مخصوصاً لمتغير ات الجنس و الحالة الزوجية و الأطفال من أجل إجراء المزيد من الاختبار ات حول دور هذه المتغيرات في تقييد اختيارات سوق العمل، كما يوحي بذلك البحث النوعي.

أما القسم التالي من الورقة، فإنه يقدم تعريفاً للعمل المنزلي ويعرض التحديات التي تو اجه التحليلات التي تجري لهذا القطاع، في حين أن القسم الثالث يمثل النتائج المستقاة من البيانات الإثتوغر افية المتعلقة بالعينة الإحصائية الصغيرة. يناقش الجزء الرابع البيانات ومنهجية البحث ومنوسطات الخصائص المرتبطة بمفردات العينات، في حين يستخدم الجزء الخامس العينات الكبيرة المستخدمة في المسوح الأسرية لكي يختبر فرضية الدراسة بطريقة تجريبية. أخيراً، يلخص الجزء السادس نتائج الدراسة ويناقش السياسات العامة الر امية إلى رفع فعالية القطاع وحماية حقوق العاملين فيه.

\section{الجزء الثاني: تعريف العمل المنزلي}

"العمل المنزلي" مفهوم تجريبي يصعب فهمه، وذلك لأنه لا يوجد أي تعريف منفرد لهذا القطاع وبسبب الافتقار إلى بيانات تساعد على بلورة تعريف دقيق له (بروغل 1997). فالتعريف الأكثر عمومية في هذا الصدد هو أن العامل المنزلي هو شخص يتخذ من منزله منطلقاً لعمله (ويغو 2000؛ أرياغادا 1998)، وهو تعريف يشمل كذلك فئة العاملين لحسابهم أنفسهم، أو العاملين بالقطعة، أو العاملين بأجر لحساب "وسيط" أو لحساب إحدى الثركات، أو العاملين بدون أجر في شركة عائلية. هذا، وقد أسفرت عدة تحسينات على هذا التعريف عن نطاق و اسع من المفاهيم الرامية إلى تحديد "العامل المنزلي" أو "العامل من منزله". فعلى سبيل المثال:

درجة التبعية: حيث يمنالك "الزبون" أو "العميل" الذي يتعامل مع العامل حق مر اقبة العامل

$$
\text { و وعلية الإنتاج (بروغل 1997؛ منظمة العمل الدولي 1995)؛ }
$$

• مستوى المخاطر : حيث يتلقى العامل راتباً ثابتاً من "الزبون" أو "العميل" ولكنه لا يخضع

$$
\text { للمخاطر المنصلة بتقلبات الأسعار أو الطلب (بروغل 1997)؛ }
$$

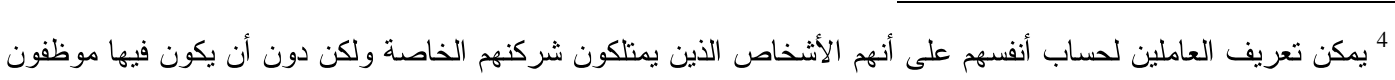




• طبيعة المخرجات: العاملون في العمل المنزلي الصناعي، إنتاج الصناعات اليدوية، إعداد وبيع

$$
\text { الأطعمة، وخدمات الاتصالات السلكية و اللاسلكية (بروغل 19997)؛ }
$$

• ملكية عملية الإنتاج: التجميع، حيث يمكن توفير المدخلات وأدوات الإنتاج من قبل صاحب

$$
\text { العمل أو الموظف بنفسه (بو لاك 1998، أرياغادا 1998)؛ }
$$

• مستوى المهارة: العاملون من منازلهم ولكنهم ليسو ا في عداد المهنيين (يصنف المهنيون في

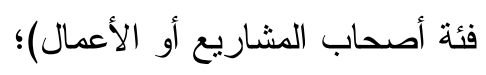

• نوع "العميل" أو "الزيون": العاملون الذين يكون عميلهم أو زبونهم وسيطاً (أي ليس الجمهور) مقابل العاملين الذين يبيعون مباشرة إلى الجمهور (منظمة العمل الدولية 1995).

يؤدي هذا التغاير الو اسع في التعريفات إلى مشكلتين في التحليل، الأولى هي أن العديد من هذه التعريفات يصعب تحديدها أو قياسها بالكم. فلى سبيل المثال، لا يمكن أن يقوم مقام "درجة التعبئة" أو "مسنوى المخاطر" سوى عدد من الخصائص الأخرى ذات العلاقة بالاستقلال في عملية اتخاذ القرار . كذللك، قد لا تتوفر للعاملين أنفسهم المعلومات الضرورية للتصنيف، فالعامل قد لا يعرف ما إذا كان الإنتاج يباع لأفر اد يستخدمونه في استعمالاتهم الخاصة أو أن المشتري سيقوم بدوره بإعادة بيع المنتج إلى عميل آخر . أي أن المسوح التي تتبع منتجاً ما من خلال السلاسل الثاملة للقيمة هي وحدها القادرة على نوفير مثل هذا النوع من المعلومات.

ثانياً، غالباً ما تلجأ الدر اسات التي تتناول العاملين من منازلهم إلى استخدام تعريفات مختلفة، مما يعيق تثكيل صورة منماسكة واحدة للقطاع. فالنتائج المتتاقضة ظاهرياً والمستقاة من البيانات النوعية، قد ثكون في الو اقع قد تحصلت جر اء استخدام أساليب مختلفة، وليس جر اء وجود اختلافات حقيقية في الحقائق قيد الدراسة. ففي غياب مجموعة متفق عليها من الخصائص اللازمة لتعريف هذا القطاع، يصبح من الصعب تصميم المسوح من أجل جمع البيانات بطريقة منتظمة حول هذا القطاع (تثين، سبستاد و أوكونل 1999). 
يأخذ الجدول (1) بالاعتبار صعوبات القياس ويبين أن نسبة القوة العاملة المنخرطة في العمل المنزلي تنراوح من 1.6 بالمائة إلى 23 بالمائة من مجموع السكان العاملين عبر العالم. وقد استخدمت في بناء هذه البيانات مجموعة من التعريفات و الأسئلة، مما يحيل المقارنات إلى أمور لا معنى لها. مع ذللك، تجدر الإثارة إلى أن العمل المنزلي موجود في البلدان النامية و المثقدمة على حدٍ سو اء. كما أن الجدول (1) يوحي بأن هذا التنظيم للعمل لا ينبع بالضرورة من العولمة، إذ أن بعض البلدان المشمولة بالجدول كان لديها قطاعات ضخمة من العاملين من منازلهم قبل قيامها بتخفيض حو اجزها التجارية.

\section{1-3 خصائص العاملين من منازلهم}

توحي الأبحاث الإثتوغر فية بأن العاملين من منازلهم هم في المقام الأول أفراد غير فادرين على، أو غير راغبين في العمل خارج منازلهم. بيد أن الأشخاص المضطرين للبقاء في منازلهم ينقسمون عموماً إلى ثلاث فئات عامة: فئة النساء (أو الرجال على نطاق أضيق) اللو اتي يتحملن مسؤوليات رعاية الأطفال أو غير ذلك

من أمور الأسرة المعيشية، وهي مسؤوليات تتطلب بقاءهن بالقرب من المنزل طيلة اليوم؛ فئة الأشخاص الذين يعانون من أوضاع بدنية أو عقلية تقيد قدرتهم على الانتقال إلى موقع العمل؛ وفئة الأفر اد الذين بعانون من صعوبة الانضمام إلى القوة العاملة بسبب قيود قانونية، أو بسبب التمييز ضدهم، أو بسبب تباين



بالنسبة للفئة الأولى ـ أب فئة الأشخاص الذين يتحملون مسؤوليات أسرية ــ نجد أن أكثر من نصف أفر ادها حول العالم هم من النساء، إذ تثير التقديرات إلى أن نسبة النساء في هذه الفئة تتراوح من 64 بالمائة إلى أكثر من 90 بالمائة، بالمقارنة مع 4 بالمائة بالنسبة لفئة غير العاملين من المنزل (منظمة العمل الدولية 1995؛ تشين سبستاد وأوكونل 1999). في أميركا اللاتينية، أفادت العاملات من منازلهن بأن ساعات العمل المرنة، وكذلك تحول المنزل إلى موقع عمل، تسمح لهن بالوفاء بمسؤولياتهن إز اء المنزل و السوق بطريقة

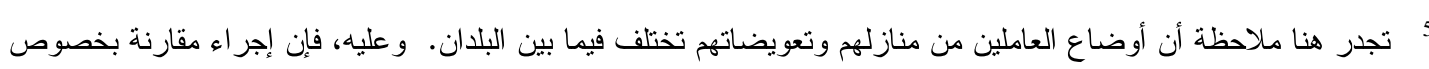

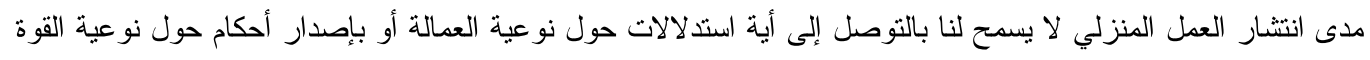
العاملة في البلدان المذكورة في الجدول (1). 
أكثر فعالية مما لو كان عملهن في موقع إنتاجي بعيد (بروغل 1999؛ نومي 2000؛ أرياغادا 1998). أما بينيريا ورولدون (1987)، فيشيران إلى أن 60 بالمائة من العاملين المكسيكيين من منازلهم والمشمولين في العينة الإحصائية التي استخدماها في دراستهما كانو اسيعتذرون عن قبول وظائف في المصانع بأجور أعلى لصالح مرونة الوقت و الموقع التي يوفرها لهم العمل من المنزل، في حين تقيد جيلين (2001) بأن عينة العاملات من منازلهن في الأرجنتين التي اختارتها لدراستها واللو اتي لديهن أطفال قد أعربن عن أملهن في العثور على وظائف خارج المنزل بمجرد خروج أطفالهن من المنزل. إن القيود التي تو اجهها هؤلاء النساء بسبب أدو ارهن كمقدات رعاية في غياب بدائل للعمل في السوق أو في القطاع العام، أو في ظل التكاليف الباهظة لتلك البدائل ــ مثل رعاية الأطفال، المياه الجارية، الأجهزة المنزلية التي توفر جهد العمل ــ تجعل العمل من المنزل شكلاً أفضل للمشاركة في سوق العمل. وبدون هذه القيود، فقد يلجأن إلى خيار العمل

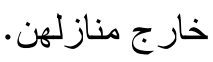

تقول إحدى الفرضيات البديلة أن النساء، حتى وإن لم توضع على عو اتقهن مسؤوليات رعاية الأطفال، إلا أن النسوة اللو اتي ينتمين إلى اسر معيشية تقليدية قد يجدن صعوبة في الحصول على إذن من أزو اجهن (أو حتى من أنفسهن) للعمل خارج المنزل. (بينيريا ورولدون 1987). لكن، عندما تكون الأدوار التقليدية الحددة وفق الفوارق بين الجنسين هي التي تحكم توزيع العمل داخل الأسرة - زوج يعمل في السوق لكي يؤمن للأسرة احتياجاتها المادية وزوجة ترعى شؤون الأسرة ــ فإن الزوج قد يشعر بتهديد أو ارتباك إذا كانت زوجته هي أيضاً تعمل، وذلك لأن ذلك الوضع قد يشير إلى عجزه عن أداء دوره كعائل منفرد للأسرة (أكرلوف وكر انتون 2002). مع ذللك، بإمكان العمل المنزلي أن يتم القيام به بصورة مستترة. أيضاً، قد تعلق على العمل من المنزل أهمية تقل عن الأهمية الني تعطى للعمل خارج المنزل ــ إذ أن الأزواج، بل و النساء أنفسهن اللو اتي يعملن من المنزل، غالباً ما يصنفون دذل المر أة من هذا العمل على أنه "مصروف جيب" للمرأة، حتى عندما يكون ذلك الدخل هو الصددر الرئيسي لدخل الأسرة (غلدستين 2001) ـ وبذلك تكون الأسرة قد حافظت على مظهر أن الزوج يقوم بدوره كعائل للأسرة على نحو وافٍ بالمر اد. 
هناك فئة ثانية من الناس الذين يعتبرون العمل من المنزل هو الأفضل بالنسبة لهم، على الرغم من القيود المفروضة عليهم، ألا وهي فئة الذين تفرض عليهم قدر اتهم البدنية و العقلية صعوبة في الانتقال إلى مواقع عمل خارج المنزل، أو في أداء عمهم في أماكن غير مهيأة لاستيعاب احتياجاتهم الخاصة. قد تشمل هذه الفئة أفر اداً من ذوي الإعاقات بغض النظر عن عمرهم (منظمة العمل الدولية 1995)، وأفراداً من كبار السن الذين فقدو ا قابلية التحرك و الانتقال بعد تقدمه في السن (كار 2000؛ تومي 2000). و هذا دليل آخر على أن العمل من المنزل قد لا يكون الثكل الأفضل من العمل، إلا أنه قد يتيح أفضل فرصة للعمل في ظل القيود

أخيراً، قد تشمل فئة العاملين من منازلهم أناسا يجدون صعوبة في دخول سوق العمل المنتظمة بسبب قيود قانونية، أو بسبب التمييز ضدهم، أو بسبب نقص المعلومات. إذ أن فئات النساء، المهاجرين، الأطفال، الأفر اد ذوي المهار ات المتدنية، والعاملين كبار السن يميلون إلى أن يجدوا صعوبة في العثور على وظائف. وتتبين هذه الصعوبة في المعدلات العالية للبطالة فيما بين هذه الفئات6. قد يعود سبب ذلك إلى عو امل جانبية تتعلق بالطلب، إذ أن أصحاب العمل غالباً ما يفترضون أن هذه الفئات أقل مهارة بسبب خبرتهم الوظيفية المحدودة، أو مستويات تحصيلهم التعليمي المتدنية، أو قدر اتهم الفطرية (وهذا يعتبر تمبيزاً محضاً)، أو لأن مهار اتهم قد آلت إلى الزو ال، أو لأن توظيفهم غير رخيص بسبب تقييدات قانونية (عمالة الأطفال، مهاجرون غير شرعيين). وبما أن العمل من المنزل لا يتطلب مهار ات عالية ويتم في منأى عن أعين أصحاب العمل (أي أنه يلتف حول المسألة القانونية) وغالباً ما يكون أجره حسب الإنتاج (أي أن المهارة أقل أهمية)، فان تحامل صاحب العمل قد أقل يصبح تفشياً في هذا العمل. من ناحية أخرى، قد لا يتوفر لهؤلاء الأفراد القدر الكافي من المعلومات حول فرص العمل أو كيفية البحث عن وظائف، وخاصة بالنسبة للنساء و المهاجرين و الأطفال، مما يجعلهم يقبلون العمل بالقطعة، الذي يوزع عليهم في الأحياء الهامشية التي يقطنونها، و لا يتيح لهم أبداً استقصاء سوق العمل بكامله (منظمة العمل الدولية 1995). ولربما يسهم كلا هذين السيناريو هين في 
بروز قوة عاملة تتذذ من المنزل منطلقاً لها وسوق عمل قد تحتكره أقلية من أصحاب العمل المتو اطئين فيما بينهم على إبقاء الأجور في مستويات متدنية وتخفيض المز ايا إلى حدودها الدنيا7.

\section{-3-3 - 2-3 طبيعة العمل}

تتباين عمليات الإنتاج ومخرجاته مع اختلاف العاملين من منازلهم، لكن معظم الدراسات النوعية تتفق على خاصيتين اثتنين تميزان هؤلاء العمال: الأولى أن أجور العاملين من منازلهم متدنية، والثانية أنهم يعملون ساعات تزيد على عدد ساعات العمل الأسبوعية القانونية8. فعلى سبيل المثال، يجد بينيريا ورولدون (1987) أن 90 بالمائة من النساء في العينة التي استخدماها في در استهما يتلقين أجوراً تقل عن الحد الأدنى. وتدعم هذا الاستتناج دراسات أخرى (ويغو كار 2000؛ منظمة العمل الدولية 1995). كذلك يتبين من دراسة ويغو (2000) ودر اسة منظمة العمل الدولية (1995) أن ساعات عمل الوردية بالنسبة للعاملين من منازلهم تتجاوز بكثير عدد الساعات الأسبوعي القانوني. ويتوصل بينيريا ورودلدون (1987) إلى النتيجة ذاتها بخصوص فئة العاملين من منازلهم الذين يكسبون معظم دخل الأسرة المعيشية. إلا أن جيلين (2001) تتوصل إلى النتيجة المعاكسة بالنسبة للعاملين من منازلهم في الأرجنتين، حيث يبلغ عدد ساعات عمل الوردية بالنسبة لهم ثلثي عدد ساعات عمل وردية العاملين الآخرين.



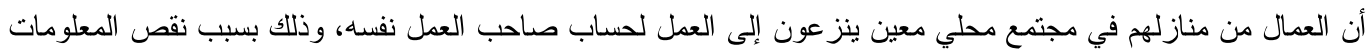

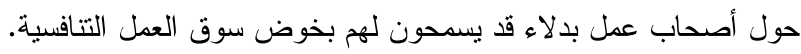

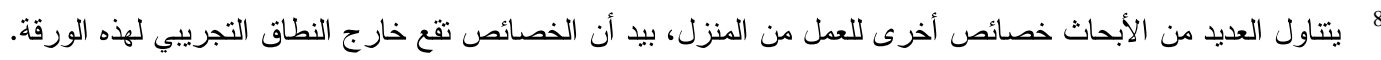

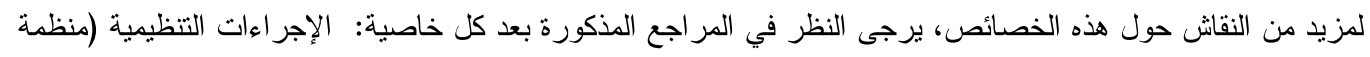

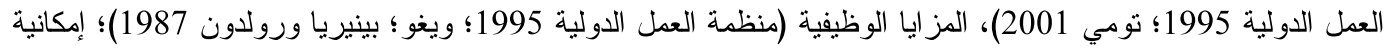



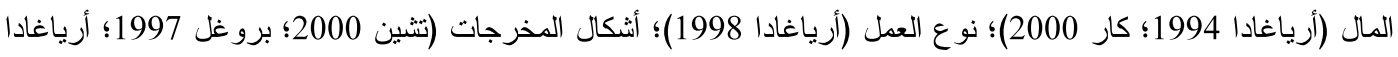
1998؛ بينيريا ورولدون 1987)، سلاسل القيمة الثاملة (تثين 1999؛ كار 1994 2000) و السياق الاجتماعي (بينيريا ورولدون 


\section{الجزء الرابع: البيانات، المنهجية، وخصائص العينة الإحصائية}

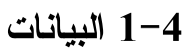

تستند الأجزاء الباقية من هذه الورقة في اختبارها للنتائج النوعية على بيانات المسوح العائلية في كل من البرازيل و الإكو ادور و المكسيك، وهي بلدان تم اختيار ها فقط على أساس توفر البيانات، التي كانت عبارة عن المسوح الوحيدة التي أمكن الحصول عليها لأسو اق العمل في أميركا اللاتينية و التي أتاحت تحديد العمل في المنزل لحساب السوق. أما مجموعات البيانات التي تم استخدامها فهي: المسوح العائلية الوطنية البرازيلية (Pesquisa Nacional de Amostra do Domicilio- PNAD) المناطق الحضرية في المكسيك (Encuesta Nacional de Empleo Urbano - ENEU) لعام 1999 (الربع الثاني)، ومسح ظروف المعيشة في الإكو ادور (Encuesta de Calidad de Vida-ECV) لعام

تقتصر العينة في جميع البلدان على رجال ونساء من المناطق الحضرية تتراوح أعمار هم من 15 سنة إلى 70 سنة9. و وقد تم تحليل بيانات الرجال بمعزل عن بيانات النساء، وذلك لأن التحليل النوعي يوحي بأن هذين النوعين من البيانات لها أنماط مختلفة للغاية في العمل المنزلي ودو افع و اضحة المعالم للانخر اط في هذا التنظيم للعمل. كما أن تحليل الانحدار يشمل فقط أولئك الذين لا يزيد تحصيلهم العلمي على الدر اسة الثانوية، أي أنه بذلك يستثي أصحاب المهن. وعليه، فإن حجم العينة هو 60 ألفاً بالنسبة للبر ازيل وما يقرب من 100 ألف بالنسبة للمكسيك. أما حجم عينة الإكو ادور فقد اثتنمل على أقل من 3000 فرد.

9 الدافع لهذا التحديد المكاني ذو شقين: أولاً، مسح ENEU يغطي سكان المناطق الحضرية. و عليه، ومن أجل إتاحة الدجال

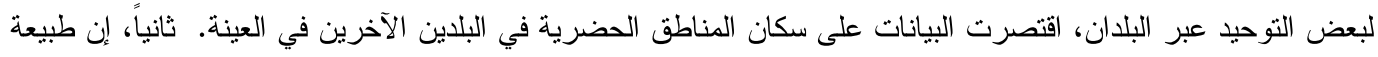

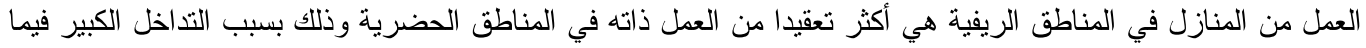

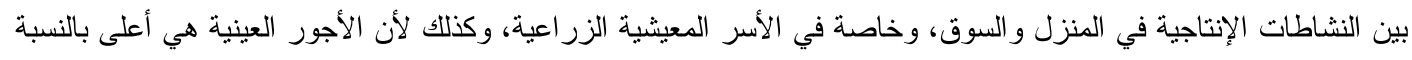

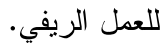


بسبب قيود البيانات، فإن الدر اسة تستخدم التعريف الأساسي أكثر من غيره للعامل من المنزل، ألا وهو أن هذا العامل هو فرد مكان عمله هو منزله. وقد أمكن من خلال المسوح التعرف على أربعة أثنكال عامة للعاملين من مناز لهم.

العاملون بصورة غير رسمية لحسابهم أنفسهم: وهم أفر اد يصرحون بأنهم يعملون لحساب

أنفسهم، وأنهم يعملون في المنزل و أن تحصيلهم التعليمي لا يتجاوز المرحلة الثانوية. المهنيون: وهم أفر اد يصرحون بأنهم يعملون لحساب أنفسهم أو موظفين لدى أنفسهم، وأنهم يعملون في المنزل وأن تحصيلهم التعليمي يتجاوز المرحلة الثانوية. العاملون بعقود: وهم أفراد يصرحون بأنهم موظفون، وأنهم يعطلون في المنزل بأجر، وأن تحصيلهم التعليمي لا يتجاوز المرحلة الثانوية، وأنهم يعملون في قطاع التصنيع 10. • العاملون بدون أجر: وهم أفر اد يعطلون من منازلهم، ولكنهم لا يتقاضون أجراً.

يبين الجدول (2) نسبة العاملين من المنازل في كل بلد من بلدان العينة موزعة حسب الجنس وفئة العمل من المنزل. أما فئة "أخرى" فتتكون من أصحاب الثركات و العاملين في الخدمات (بما في ذلك الخدم و الخادمات في البيوت) و العمال الزر اعيين.

يشكل العاملون من المنزل جزءاً جوهرياً من القوة العاملة. في العام 1999، كان حو الي 5 بالمائة من القوى العاملة في البرازيل و المكسيك (وكذلك 10 بالمائة من القوى العاملة في القطاع غير الرسمي) و أكثر من 17 بالمائة من القوى العاملة الإكو ادورية، يعملون من منازلهم. أما أرجحية كون النساء في البلدان الثلاثة عاملات من منازلهن فتقوق أرجحية عمل الرجال من منازلهم بأكثر من ثلاث مرات.

10 إن عدداً كبيراً من الموظفين الذين لا يتجاوز تحصياهم التعليمي المرحلة الثانوية، و الذين يز عمون بأنهم يعطون في المنازل،

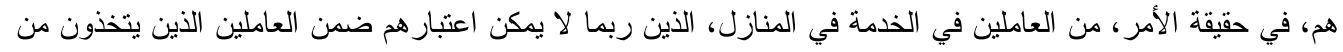

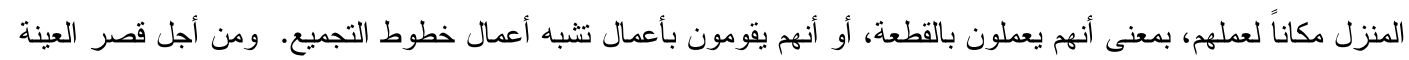
على أولئك الذين يعملون في الأشكال النقليدية للعمل من المنزل فقد اقتصرت هذه الفئ الفئة على قطاع التصنيع. 
يعمل معظم العاملين من منازلهم بصورة غير رسمية لحساب أنفسهم. ففي البرازيل و المكسيك، نجد أن حو الي 3 بالمائة من القوة العاملة هم أفراد ممن لا يتجاوز تحصيلهم التعليمي الدراسة الثانوية يعملون لحساب أنفسهم ويتخذون من المنزل مكاناً لعطهم. وهذه النسبة هي الضعف تقريباً في الإكو ادور، حيث تشكل هذه

الفئة أكثر من 7 بالمائة من القوة العاملة. و النساء أكثر أرجحية من الرجال لشغل مثل هذا الموقع. أما الفئات الأخرى من العاملين من منازلهم، فتشكل أقل من 1 بالمائة من القوة العاملة، باستثناء الإكو ادور ، حيث نجد أن حو الي 4 بالمائة من القوة العاملة هم في عداد العاملين من منازلهم بدون أجر 11.

سيأخذ ما تبقى من البحث بالاعتبار فقط أصحاب الأعمال غير الرسميين و العاملين بعقود الذين لم يتجاوز تحصيلهم التعليمي مستوى الدر اسة الثانوية، وذلك بسبب الأعداد القلبلة للمهنيين و العمال بدون أجر ، وبسبب أوضاعهم الفريدة ـ حيث أن المهنيين يمتلكون ر أس مال بشري أكبر ، في حين قد يكون العمال بدون أجر قد بلغو ا عن أجور هم بصورة غير دقيقة.12.

\section{2-4 الخصائص السكانية للعاملين من منازلهم في العينة}

يبين التحليل أن تمثيل النساء في قطاع العمل من المنزل مفرط في البلدان الثلاثة (الجداول 3أ-3ب). ففي المكسيك، نجد أنه في حين أن النساء يشكلن 35.5 بالمائة من جميع العاملين، إلا أنهن يشكلن ما يقرب من 64.8 بالمائة من أصحاب المشاريع غير الرسميين وحو الي 41.9 بالمائة من العاملين بعقود. وقد تبين أن

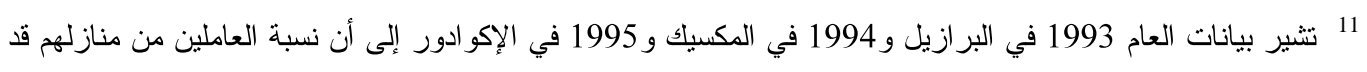

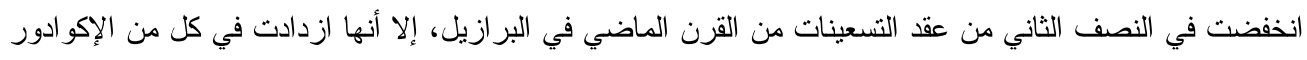

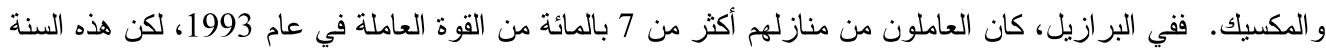





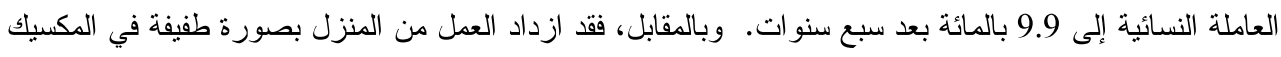

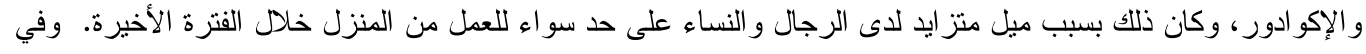

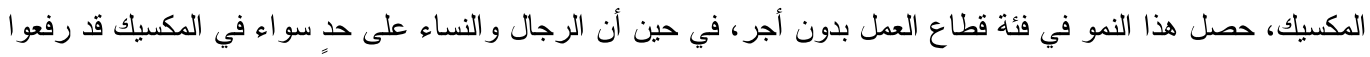
معدلات العمل غير الرسمي لحساب العاملين أنفسهم.

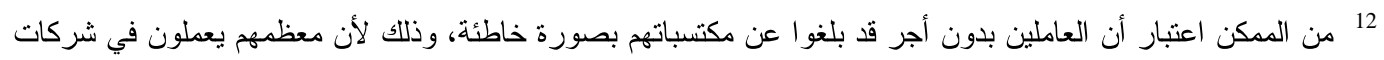

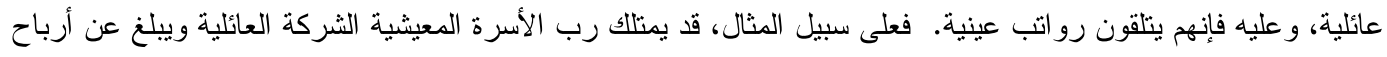

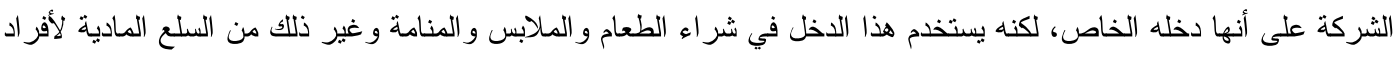

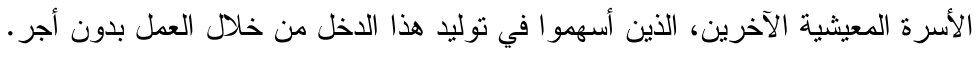


هذه النسب أعلى في البر ازيل، حيث تبلغ 74.7 بالمائة و 81.7 بالمائة بالترتيب، وذلك بالمقارنة مع 39.6 بالمائة في القطاعات الاقتصادية الأخرى. أما في الإكوادور، فتصل هاتان النسبتان بالترتيب إلى 74.1 بالمائة و 61.5 بالمائة، بالمقارنة مع 34.9 بالمائة من جميع العاملين.

عموماً، يمتلك العاملون من المنزل رأسمالاً بشرياً يقل عن ما يمتلكه العاملون في بقية الاقتصاد. فأصحاب المشاريع في القطاع غير الرسمي يميلون إلى أن تكون أعمار هم أكبر، أي أنهم بذلك يميلون إلى أن تكون خبر اتهم العملية المتملة أكبر مما يمتلكه العاملون في القطاعات الأخرى من الاقتصاد، في حين أن العاملين بعقود هم خليط من هذا وذاك. إن 8.5 بالمائة فقط من أصحاب المشاريع غير الرسميين في المكسيك، وحو الي 11.6 بالمائة في البرازيل، وحو الي 7.1 بالمائة في الإكو ادور هم في الفئة العمرية 15-25 سنة، في حين أن حو الي 30 بالمائة من أصحاب المشاريع في القطاعات الاقتصادية الأخرى هم في هذه الفئة العمرية. مع ذلك، فإن حو الي نصف جميع العاملين بعقود في المكسيك هم في الفئة العمرية الثابة، في حين أن العمال بعقود في البرازيل هم أكثر احتمالاً لأن يكونو افي الفئة العمرية 26-45 سنة، أب أنهم عمال في ريعان عمر هم. أما في الإكو ادور، فإنهم يميلون إلى أن يكونوا في الفئة العمرية الأكبر من غيرها، وهي فئة 46 سنة أو أكثر. كذللك، تميل مستويات التعليم إلى أن تكون أقل من مسنويات التعليم في بقية الاقتصاد، وخاصة فيما بين العاملين بعقود.

يبين التحليل كذلك أن النساء المتزوجات والأشخاص الذين لا يعتبرون أرباب عائلة هم الأكثر أرجحية لأن يكونو ا عاملين من المنزل. ففي المكسيك، تبين أن 35.5 بالمائة من أصحاب المشاريع في القطاع غير الرسمي و 20.4 بالمائة من العاملين بعقود هم زوجات، في حين أن هاتين النسبتين هما 49.7 بالمائة و 60 بالمائة بالثرتيب في البرازيل، وتبلغان 31.2 بالمائة و 23.1 بالمائة بالترتيب في الإكو ادور . وبالمقارنة، نجد أن المنزوجات لا يشكلن سوى 13.8 بالمائة من العمال المكسيكيين الذين يعملون خارج المنزل، وحوالي 19.6 بالمائة من هذه الفئة في البرازيل وحو الي 13.3 بالمائة في الإكوادور. أما الاستثناء الوحيد الذي يظهر من البيانات فهو أن نسبة العمال المكسيكيين بعقود، الذين يعرفون أنفسهر على أنهم ذكور غير متزوجين، هي أعلى من نسبة النساء اللواتي يعرفن أنفسهن على أنهن منزوجات: 34.4 بالمائة مقابل 20.4 
بالمائة. ويعرف أقل من نصف العاملين من المنزل أنفسه كأرباب عائلة. كننا نجد في المكسيك فقط أن احتمالات كون أصحاب المشاريع غير الرسمية أرباب عائلة هي الاحتمالات نفسها بالنسبة للعاملين في بقية الاقتصاد. أما في البلدين الآخرين، فإنهم أقل احتمالاً بنسبة 6-10 بالمائة لأن يكونو أرباب عائلة. من جهة أخرى، نجد أن العاملين بأجور هم أقل احتمالاً لأن يكونو أرباب عائلة، حيث أن حوالي 20 بالمائة في كل بلد هم أرباب عائلة. و هذا يعكس النسب العالية من النساء و الزوجات في هذه الفئة.

العاملون بعقود في كل من المكسيك والبرازيل هم أكثر احتمالاً من العاملين في الاقتصاد ككل، أو من أصحاب المشاريع غير الرسمية، لأن يكون لايهم في المنزل أطفال في الفئة العمرية (0-12 سنة). فحوالي 29 بالمائة من العاملين المكسيكيين لديهم أطفال أعمار هم 0-5 سنو ات في أسرهم المعيشية، في حين أن أكثر من 40 بالمائة لايهم أطفال أعمار هم 6-12 سنة أو 13-18 سنة يعيشون معهم في المنزل. وهذه النسب مثابهة للنسب المتعلقة بأصحاب المشاريع غير الرسمية العاملين من منازلهم في المكسيك، لكن نسبة الأطفال في الفئة العمرية (0-5 سنو ات) و الفئة العمرية (13-18 سنة) هي أعلى بحوالي 10 نقاط مئوية بين العاملين بعقود من المنزل في المكسيك وبحو الي 20 نقطة مئوية للأطفال في الفئة العمرية (6-12 سنة). و وتبرز اختلافات مشابهة في البرازيل. أما في الإكوادور، فإن العاملين من المنزل هم أكثر احتمالاً ببضع نقاط مئوية من العاملين خارج المنزل لأن يكون لديهم أطفال في الأسرة المعيشية، لكن الاختلافات ليست بالاتساع نفسه في المكسيك و البرازيل 13

\section{4-3 خصائص التوظيف بالنسبة للعاملين من منازلهم في العينة}

العمال من منازلهم أقل احتمالاً من غير العاملين من المنزل لأن يكونو ا في القطاع الرسمي، لكن النسب تختلف فيما بين البلدان الثلاثة المشمولة في العينة (الجداول 4أ-4ج). ففي البرازيل و الإكو ادور، تبين أن حو الي 7 بالمائة من العاملين بعقود يتمتعون بمز ايا يقدمها لهم أصحاب العمل، وذلك بالمقارنة مع 58.4 بالمائة من البرازيليين و 31.7 بالمائة من الإكو ادوريين الذين لا يعملون من منازلهم. من ناحية أخرى، فقد

13 حجم عينة العمال بعقود في الإكو ادور صغير ، وعليه فإن النسب لا تختلف بدلالة إحصائية بين العمال والفئات الأخرى من




أفاد حو الي 20 بالمائة من العاملين من منازلهم في المكسيك أنهم يعملون لحساب صاحب عمل رسمي، وذلك مقابل 45.9 بالمائة من العمال الآخرين 14.

العمال بعقود الذين يعملون من منازلهم هم أكثر احتمالاً من العاملين في موقع عمل رسمي لأن يكونوا موظفين لاى شركات صغيرة"15. فحو الي 45-80 بالمائة من العاملين بعقود من منازلهم يعملون لدى شركات فيها خمسة موظفين أو أقل، في حين أن النسب هي أقل بأكثر من 20 نقطة مئوية بالنسبة لغير العاملين من منازلهم. و وبالمقابل، فإن الحصة في الثركات الني يعمل فيها أكثر من 10 موظفين (15 موظف في حالة المكسيك) هي أقل بالنسبة للعمال من المنزل منها بالنسبة لغير العاملين من المنزل في المكسيك و البرازيل، في حين أن هذه النسب منساوية تقريباً في الإكو ادور. وقد يعود السبب في هذه النسبة العالية في الثركات الصغيرة إلى أن العاملين بعقود قد حددوا أن أصحاب العمل هم "الوسطاء"، الذين عادة ما يتلقون الطلبيات (أو امر التشغيل) من الثركات ومن ثم يعهدون بتتفيذها إلى المنتجين (أرياغادا 1998).

يتلقى كل من العاملين بعقود و أصحاب الثركات غير الرسميين الذين يعملون من منازلهن أجوراً ساعية (بالساعة) أقل من الأجور الساعية للعمال الذين لا يعملون من منازلهم. وباستخدام الأجر القانوني الأدنى في الفترة الأولى بالنسبة لكل بلد كوحدة للقياس (مما لا يسمح لمقارنات عبر البلدان)، نجد أن نسبة عالية من العاملين من المنازل يكسبون أجراً يقل بقيمة أجر أدنى واحد عما يكسبه غير العاملين من منازلهم، في حين أن نسبة أقل تكسب أجراً يزيد على ثلاثة أضعاف الأجر الأدنى.

أخيراً، يفيد العمال من منازلهم بأنهم يعملون ساعات تقل عما يعطله الأفراد العاملين خارج منازلهم. ففي البرازيل و المكسيك، يقضي أصحاب المشاريع المنزلية و العمال بعقود حو الي 36 ساعة أسبو عياً في عملهم، مقارنة مع ما يقرب من 46 ساعة بالنسبة للمكسيكيين غير العاملين من منازلهم وحو الي 37 ساعة بالنسبة

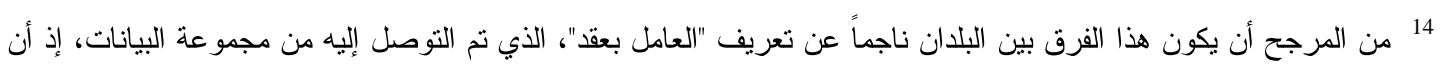

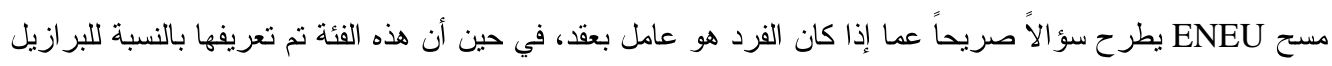
و الإكو ادور على أنها فئة العامل من منزله الذي يصف فئته المهنية على أنها "التصنيع".

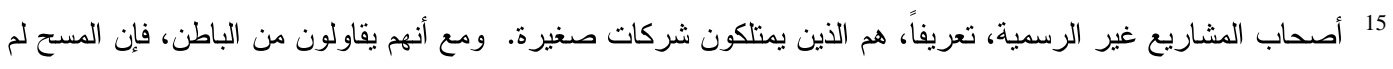
يوجه إليهم أسئلة حول حجم الثركة التي يتعاقدون معها. 
لنظر ائهم في البر ازيل. أما في الإكو ادور، فإننا نجد أن التفاوت أكبر بالنسبة للعمال من منازلهم الذين يفيدون بأن أسبوع العمل بالنسبة لهم هو 32.3 ساعة في المتوسط، بالمقارنة مع 43 ساعة بين العاملين خارج منازلهم 16. هذا الوضع يشبه ما توصلت إليه جيلين (2001) بالنسبة للأرجنتين، لكنه يتعارض مع الأدبيات النوعية الأخرى (ويغو 2000؛ منظمة العمل الدولية 1995). وقد يكون هذا التناقض ناتجاً عن أخطاء في التبليغ بسبب الطبيعة المتقطعة للعمل من المنزل، وعن الصعوبة في تحديد النشاطات من حيث كونها نشاطات سوق أم غير ذلك، وعن الوظائف المتعددة التي غالباً ما ينخرط فيها العاملون من منازلهم (بينيريا ورولدون 1987)، وعن التمازج فيما بين نشاطات العمل في السوق ونشاطات العمل في المنزل، مما يضفي صعوبة على تقدير الوقت المصروف في العمل في السوق في الأسبوع المرجعي، وعن مشاركة أفراد الأسرة

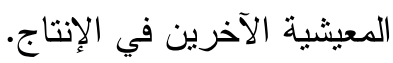

\section{4-4 المنهجية}

تستخدم هذه الورقة منهيات التحليل الاتحداري البسيطة لكي تحدد بطريقة أفضل الخصائص التي تؤدي بالعامل إلى التوجه نحو العمل من المنزل، ولكي تحدد كذلك ما إذا كانت أجور وساعات عمل العاملين من منازلهم أقل من أجور وساعات عمل غيرهم من العمال، وربط ذلك بحقيقة ميلهم إلى أن يكونوا أقل تعليماً وأن تكون لديهم مسؤوليات عائلية. وقد تشكلت العينة من القوة العاملة برمتها، في الفئة العمرية (15-70 سنة)، الذين يحددون مكان عملهم ويصرحون بأجور هم وساعات عمله. وتبين الجداول 3أ-3ج الوصف

لقد تم تحديد خصائص العاملين من منازلهم باستخدام نموذج "لوجيت" من أجل تقدير احتمال كون العامل يتخذ من منزله مقراً لعمله، حيث كانت لفظة منزل متغيراً رمزياً قيمته 1 إذا كان الفرد يعمل في بيته وصفر إذا لم يكن كذلك 17. بعد ذلك تم إخضاع المتغير الثابت للتحليل الانحداري على المتغيرات السكانية المدرجة في 16 انخفض عدد ساعات العمل الأسبو عي بين عام 1995 وعام 1999 بالنسبة للعاملين من منازلهم، ولكن ليس بالنسبة للعاملين خار جنازلهم. 17 في المكسيك تضمن مسح ENEU سؤ الاُ طلب من المستجيب تصنيف المكان الذي تتم فيه النشاطات ذات الصلة بالعمل، وكان أحد الخيارات "في منزلك الخاص". أما في البرازيل، فقد وجه مسح PNAD السؤ الال الثالي: "مؤسسة العمل تقع في ..." 
الجداول 3أ-3ج. وفي الوقت ذاته، تأخذ لفظة أنثى قيمة 1 إذا كان الفرد المستجيب أنثى. أما المتغيرات العدر 15، العدر 26-45، والعدر 46، فهي متغيرات رمزية تأخذ القيمة 1 إذا كان عمر المستجيب ضمن تلك الفئة. هذا، وقد تم حذف المتغير الرمزي الأخير. وفي البلدان الثلاثة، كانت لفظة لا تعليم متغيراً رمزياً قيمته 1 إذا كان الفرد لم يلتحق أبداً بمدرسة؛ في حين كانت لفظة ابتدائي متغيراً رمزياً قيمته 1 إذا كان الفرد قد أنهى ما لا يزيد على ست سنوات من الدراسة في المكسيك و الإكو ادور (8 سنوات في البرازيل). وكان المتغير الرمزي المحذوف و المتعلق بالتعليم هو 7-12 سنة من الالتحاق بالمدارس في المكسيك و الإكو ادور و 9-11 سنة في البرازيل. و تأخذ لفظة رب أسرة في المتغير الرمزي قيمة 1 إذا كان الفرد قد أفاد بأنه رب الأسرة. ولضبط النتائج وفق القيود الأسرية و/أو أي عمل إضافي يحتمل أن يكون منتجاً، اثنمل المسح على متغير ات رمزية أخرى هي: adult, teen, elemsch, presch، حيث تأخذ لفظة presch قيمة 1 إذا كان في الأسرة المعيشية أطفال أعمار هم 5 سنوات أو أقل، ولفظة elemsch تأخذ قيمة 1 إذا كان في الأسرة المعيشية أطفال تتر اوح أعمار هم من 13 سنة إلى 18 سنة، ولفظة adult تأخذ قيمة 1 إذا كان في الأسرة بالغون (غير متزوجون) عمر هم 19 سنة أو أكبر . ويأخذ متغير متزوج married قيمة 1 إذا كان المستجيب قد ذكر أنه يعيش ضمن رباط الزوجية أو ضمن علاقة نو افقية مع شخص آخر و القيمة صفر بخلاف ذلك. وبالنسبة للانحدارات البرازيلية، تمت إضافة المتغير الرمزي ملون (غير أبيض) non-white لضبط النتائج وفق العرق (الجنس البشري)، حيث يأخذ هذا المتغير القيمة 1 إذا كان المستجيب قد عرف نفسه على أنه أسود (preto) أو مختلط الأعراق (pardo). ولم يكن هذا المتغير منوفراً بالنسبة للمكسيك و الإكو ادور. وقد female تمت عملية تقدير الانحدار ثلاث مرات لكل بلد، الأولى شملت العينة برمنها (حيث كان متغير أنثى هو الأكثر أهمية من سو اه) ومن ثم حسب الجنس sex (كون المستجيب ذكراً أم أنثى) 18.

من أجل اختبار ما إذا كان العاملون من منازلهم يكسبون أجوراً تقل عن غيرهم من العمال أم لا لمجرد أنهم يتخذون من المنزل مقراً لعملهم، أو ما إذا كانت الفروق في الأجور عائدة لخصائص رأس المال البشري، فقد

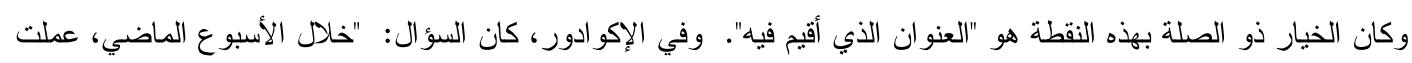








تم إخضاع أجر الساعة المسجل (الدخل بالنسبة للعاملين لحساب أنفسهم) الذي يكسبه العاملون من منازلهم و غير العاملين من منازلهم لتحليل انحداري على المتغيرات التي تحدد إنتاجية سوق العمل أو المتغيرات التي قد يستخدما أصحاب العمل لغرض التمييز في الأسعار فيما بين فئات العاملين: العمر، العرق، الجنس ومستوى التعليم. أما المتغير الذي يثير الاهتمام في الانحدار فهو متغير home 19 . وقد تم على حدة تقدير الانحدار في العينة الكاملة، وفي عينة الرجال وفي عينة النساء.

يتكرر هذا التمرين بتقدير أجر الساعة حسب السجلات شريطة أن يكون المستجيب ضمن القوة العاملة. ولهذا الغرض فقد نم استخدام طريقة اختبار هكمان ذات الخطوتين، حيث الخطوة الأولى هي تقدير أرجحية كون المستجيب داخلاً في القوة العاملة، ومن حيث حساب معامل تصحيح لكل مشاهدة وشموله كمتغير مستقل



أخير اً، ومن أجل اختبار ما إذا كان العاملون من منازلهم يعملون ورديات أطول أو أقصر من الورديات التي يقوم بها عمال يخضعون لنفس القيود ويعملون خارج منازلهم، فقد نم إخضاع سجل ساعات العمل لتحليل انحداري حسب الجنس، العمر، رئاسة الأسرة، وخصائص أخرى للأسرة المعيشية و التي قد تقيد وقت سوق home العمل (الحالة الزوجية، وجود أطفال من مختلف الأعمار، وجود أفراد بالغين آخرين) ومتغير الرمزي. ومرة أخرى، كان المتغير الرمزي home هو المتغير الرئيسي الذي حظي بالاهتمام.

الجزء الخامس: نتائج التحليل الاحداري

1-5 خصائص العاملين من منازلهم

تدعم نتائج التحليل الانحداري للبلدان الثلاثة بقوة نتائج الأدبيات النوعية القائلة بأن النساء يسيطرن على قطاع العمل من المنزل (العمود 1 في الجداول 5-أ - 5ج). حتى عند ضبط النتائج حسب القيود الأسرية التي 19 يمكن القول بأن الأفر اد الذين يصبحون عاملين من منازلهم لهم خصائص معينة لها صلة بالأجور المتنية، وعليه فإن الانحدار

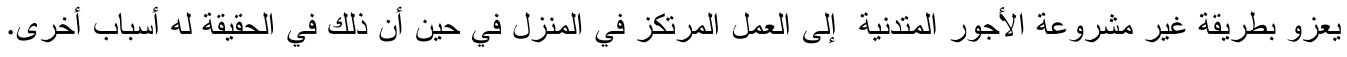

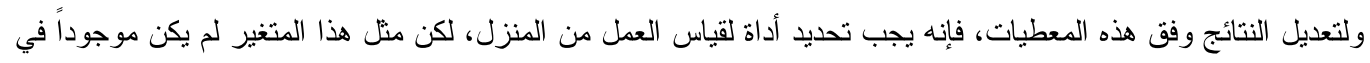


غالباً ما تحدد استخدامات المر أة للوقت، ناهيك عن استخدامات الرجل للوقت - وجود أطفال أو زوج/زوجة - فإن النساء أكثر احتمالاً من الرجال للعمل في المنزل بنسبة 4.4 بالمائة في المكسيك، 8.8 بالمائة في البرازيل، و22.9 بالمائة في الإكو ادور .20 - 20

كما أن النتائج تدعم كذلك ما تم التوصل إليه من أن الأثخاص الذين يحملون على عاتقهم مسؤوليات منزلية أكبر هم أكثر احتمالاً للانخر اط في العمل من المنزل، أبي النساء اللواتي يتحملن مسؤوليات منزلية والأفر اد الأكبر سناً. وبدون التباس، فإن النساء الخاضعات لقيود أسرية هن أكثر احتمالاً للتوجه نحو العمل من المنزل من النساء اللواتي ليس لديهن أزواج أو أطفال (العمود الثالث في الجداول 5أ-5جـ) و المكسيك، نجد أن النساء المتزوجات هن أكثر احتمالاً من غير المتزوجات للعمل من منازلهن بحوالي 3 بالمائة. أما في الإكو ادور، فالمعامل موجب، ولكنه لا ينطوي على دلالة إحصائية، ولربما كان ذلك بسبب صغر حجم العينة22. أما بخصوص الأطفال، فقد كانت النساء المكسيكيات و البرازيليات، اللواتي لديهن أطفال في الفئة العمرية (0-5 سنو ات) أكثر احتمالاً بحو الي 2 بالمائة لأن ينخرطن في العمل من المنزل من النساء بدون أطفال في أسرهن المعيشية. أما النساء اللو اتي لديهن أطفال في الفئة العمرية (6-12 سنة) فقد كانت أرجحية انخر اطهن في العمل من المنزل أكثر بحو الي 10 بالمائة لأن يصبحن عاملات من المنزل. و وقد تبين أن تقدير المعامل للأطفال في الفئة العمرية (0-5 سنوات) كان موجباً وذا دلالة إحصائية عند مسنوى 10 بالمائة، موحياً بذلك أن هؤلاء النساء أكثر احتمالاً للتوجه نحو العمل من المنزل بحو الي 6 بالمائة. من جهة أخرى، أظهر الرجال نزعات ضعيفة نحو العمل من المنزل، وذلك نتيجة خصائص الأسرة المعيشية، فقد كانت مشاركتهم في العمل من المنزل غير مرتبطة بالزواج و لا بوجود أطفال صغار و لا حتى مرتبطة سلبياً بهذين المتغيرين.

20 ازدادت هذه الاحتمالات في المكسيك والإكو ادور بين العام 1994 (1995 بالنسبة للإكو ادور) و العام 1999 في حين أنها

انخفضت في البرازيل.

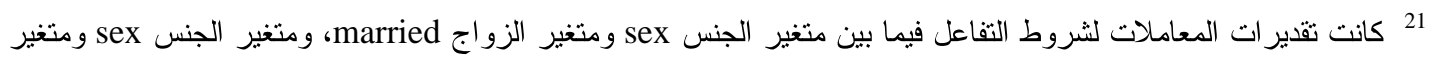

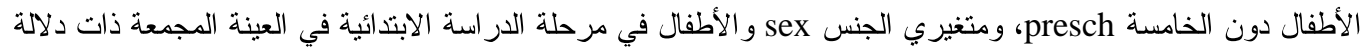

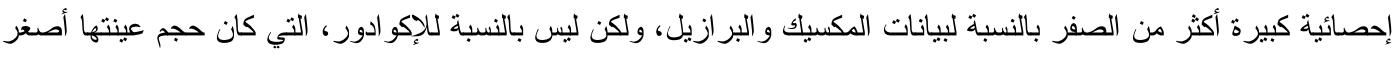
بكثير . 22 باستخدام بيانات 1995 من الإكو ادور، و وعلى الرغم من صغر حجم العينة، يتبين أن النساء المتزوجات هناك كن أكثر احتمالاً للعمل من منازلهن بنسبة 6.9 بالمائة. وقد كان للمعامل دلالة إحصائية كبيرة عند مستوى 5\% 
حتى عند ضبط النتائج حسب وجود الأطفال، فقد تبين أن النساء الأقل تعليماً كان لايهن ميل نحو العمل من المنزل في البرازيل و المكسيك (بنسبة 12 بالمائة و 6 بالمائة على الترتيب فيما يتعلق بفئة النساء اللواتي لم يلتحقن بالددارس أبداً وفئة النساء اللواتي لم يتجاوز تحصيلهن التعليمي الدراسة الابتدائية)، في حين كان معامل التعليم بالنسبة للرجال صغيرًا جداً. إن هذه التأثيرات، القوية بالنسبة للرجال و الغائبة بالنسبة للنساء، توحي بأن التعليم وحده لا يؤدي إلى العمل من المنزل. بدلاً من ذلك، لربما كان المزج بين كون الفرد امرأة وكونها غير متعلمة هو الذي يؤدي إلى قيمة أعلى لعملها المنزلي لأن الأسر غير المتعلمة تميل إلى أن تكون فقيرة (وودون 2000) والأسر الفقيرة تنزع إلى أن يكون لديها عدد أقل من أجهزة توفير العمل وعدد أكبر من الأطفال (وودون 2000).

تبين النتائج أن الأفر اد الأكبر سناً أكثر احتمالاً لأن يكونو ا عاملين من منازلهم، مما يدعم النتائج النوعية القائلة بأن الأفر اد من ذوي المهارات المتقادمة والقدرة المحدودة على الانتقال يميلون إلى العمل في المنزل. فأرجحية كون الفرد عاملاً من المنزل تزداد باطر اد مع التقدم في السن بالنسبة للرجال و النساء على حدٍ سواء وفي البلدان الثثاثة، حيث أن احتمالات قبول النساء الأصغر سناً لهذا النوع من العمل في البرازيل و الإكو ادور بعيدة على وجه الخصوص. و هذا يعكس النزعة لدى العاملين لحساب أنفسهم في القطاع غير الرسمي، و الذين يشكلون حصة كبيرة من العاملين من منازلهم في العينة، إلى أن يكونو ا عمالاً أكبر سناً (كننغهام ومالوني 2001). (ك)

تتوفر أدلة أقل على أن الإمكانيات المحدودة في الوصول إلى سوق العمل، سواء أكانت ثلاك المحدودية بسبب قيود الطلب أو قيود العرض، تقود الناس إلى العمل من المنزل. فالتحليل الانحداري للبيانات البرازيلية يبين أن الأفر اد الملونين (من الجنس غير الأبيض) ليسوا أكثر احتمالاً ولا أقل احتمالاً لأن يكونو اعاملين من المنزل بالمقارنة مع العمال البيض (المفضلين). 
يثقاضى العاملون من المنزل، سواء أكانو ارجالاً أم نساء، أجوراً ساعية أقل من تلك التي يتقاضاها غير العاملين من منازلهم في البلدان الثثلاثة. و عند ضبط النتائج حسب الاختلافات في رأس المال البشري، يتبين

أن العاملين من منازلهم يثقاضون أجوراً تقل عن أجور غير العاملين من المنزل بحو الي 22 بالمائة (21) بالمائة بعد تصحيح تقدير ات الاختيار) في البرازيل، وحو الي 26 بالمائة (20 بالمائة بعد التصحيح) في الإكو ادور ، وحو الي 19 بالمائة (21 بالمائة بعد التصحيح) في المكسيك323. أما علاوة موقع العمل الممنوحة للنساء العاملات فهي أكبر من ثلك الممنوحة للرجال، حيث أن النساء العاملات من منازلهن يكسبن أجوراً ثقل بحو الي 26 بالمائة (11 بالمائة بعد تصحيح تقديرات الاختيار) عن ما تكسبه النساء غير العاملات من منازلهن في البرازيل، وحو الي 41 بالمائة (21 بالمائة) في الإكو ادور ، وحو الي 27 بالمائة (29 بالمائة) في المكسيك. من جهة أخرى، تبين النتائج أن التفاوتات بالنسبة للرجال هي في نطاق علاوة بنسبة 0-17 على

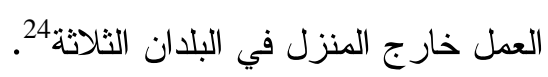

مع أن وجود أطفال وزوج يسبب انخفاضاً في دخل النساء و العاملات عموماً، إلا أن وجود زوج فقط يسبب انخفاضاً في أجور النساء العاملات من منازلهن بنسب أكبر. فقد تبين من النتائج أن تقدير ات المعامل بالنسبة للتفاعل فيما بين متغير home ومتغير married كانت سالبة في البلدان الثلاثة جميعها و أنها كانت ذات دلالة إحصائية في البر ازيل و المكسيك. بيد أن شرط التفاعل فيما بين متغير home ومتغير ات الأطفال لم تكن به أية دلالة إحصائية في أي من البلدان الثلاثة. كما أن أجور الرجال العاملين من منازلهم لم تختلف حسب الحالة الزوجية أو الأطفال عن أجور الرجال العاملين خارج منازلهم.

23 عند تجزئة العينة حسب نوع العامل من منزله، يتبين أن العاملين من منازلهم بأجر في المكسيك والإكو ادور يتقاضون أجوراً



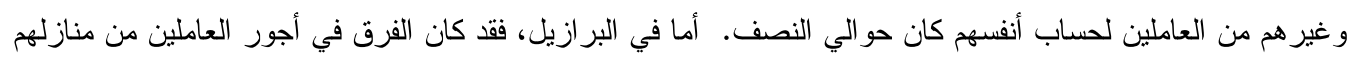

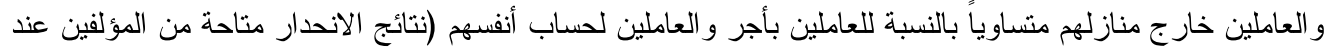


لعل الفجوة بالنسبة للنساء تعكس علاوة تعويضية على الأجر . فالبيانات المستقاة من مقابلات أجريت في أميركا اللاتينية تبين أن النساء يفضلن العمل من المنزل، وذلك بسبب مرونته و الفرصة التي يتيحها لهن للوفاء بمسؤولياتهن تجاه المنزل و السوق على حدٍ سو اء. وعليه، فقد يكون في ذلك تعويض للنساء اللو اتي يعملن خارج المنزل عن السلع و الخدمات (للاستهلاك الذاتي) الضائعة عليهن و التي كان من المكن أن يقمن بإنتاجها لو لم يكن عليهن قضاء وقت في الانتقال إلى موقع العمل، أو لو أنه كان بمقدرهن أخذوقت استر احة من العمل في السوق للقيام بأعبائهن المنزلية طيلة ساعات اليوم. وعليه، فإن النساء اللواتي يعملن من المنزل "يدفعن" ثمن مز ايا المرونة في جدول عملهن وفي أماكن العمل، وذلك عن طريق الأجور الأدنى 25

- 2-5

على نقيض النتائج النوعية، ولكن بطريقة تدعم التقديرات غير المشروطة في الجداول 4أ4ج، نثير البيانات إلى أن أسبوع عمل العاملين من منازلهم أقصر من أسبوع عمل غير هم. حتى عند ضبط النتائج حسب بدائل قيود الوقت (وجود أطفال و الحالة الزوجية) في المكسيك و الإكو ادور، فإن ساعات عمله الأسبوعي تقل بحو الي الثلث عن الوقت الذي يمضيه غير العاملين من منازلهم في العمل، في حين أنهم في البرازيل يقضون وقتاً يقل بحو الي الربع في عمهم. وذذا في الدقام الأول مرده ورديات النساء، حيث أن ساعات عمل النساء في البلدان الثلاثة تقل بحو الي 32-46 بالمائة عن ساعات عمل النساء اللو اتي يعملن خارج المنزل. من ناحية أخرى، يعمل الرجال العاملون من منازلهم ساعات تقل بنسبة 9-18 بالمائة عن الساعات التي يعملها نظر اؤهم من غير العاملين في منازلهم 26.

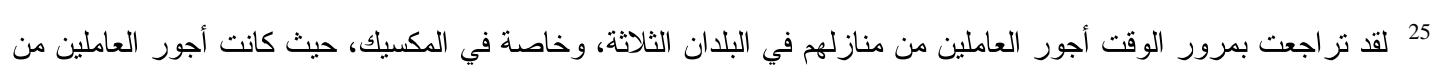

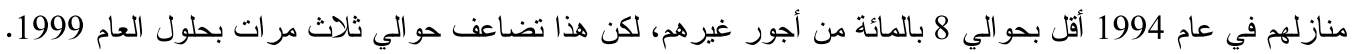

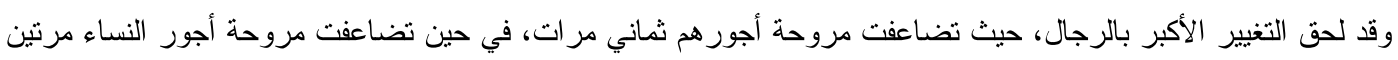



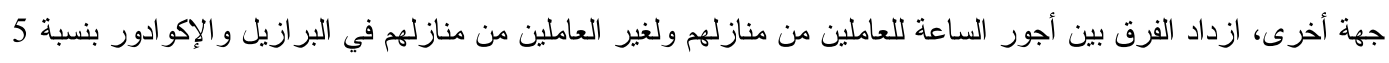
نقاط مئوية. وقد وقع التغيير في المقام الأول على مروحة الأجور بين العاملات من منازلهن وغير العاملاتلات من منازلهن،


26 لقد تقلص بمرور الزمن التفاوت في ورديات العمل في كل من المكسيك والبرازيل، لكنه ازداد في الإكو ادور. 
في المكسيك و البر ازيل، يؤثر بنيان الأسرة على الوقت الذي يمضيه الرجال و النساء في العمل من المنزل، لكن الوقت الذي يقضونه في العمل ما زال أقل من الوقت الذي يقضيه في العمل نظر اؤهم من العاملين خارج المنزل. فالرجال العاملون من منازلهم، إذا كانو ا متزوجين أو لديهم أطفال، يعملون ساعات أطول في الأسبوع مما يعمله الرجال الذين ليس لديهم زوجة أو أطفال. و وعلى العكس من ذلك، تعمل النساء المنزوجات ساعات تقل بحو الي 3 بالمائة عن عدد ساعات عمل النساء غير المتزوجات. ومما يبعث على الاستغراب أن وجود أطفال لا يؤثر على الوقت الذي تقضيه النساء في العمل من المنزل بأكثر مما يؤثر فيه على وقت العاملات خارج الأسرة المعيشية (و الاستثناء هنا هو أطفال المرحلة التي تسبق سن الدراسة في البرازيل).

الجزء السادس: الاستنتاجات

لقد بينت هذه الورقة أن العديد من النتائج التي توصلت إليها الدراسات النوعية حول العمل من المنزل يمكن دعمها من خلال الدراسات الميدانية التي تعتد على عينات عشو ائية كبيرة. فالنساء أكثر احتمالاً لأن يتوجهن نحو العمل من المنزل، وهذا سببه دورهن كأمهات وزوجات، بل ونساء عموماً. فالزوجات يخترن هذا النوع من العمل من أجل مو ازنة عملهن في السوق وفي المنزل بطريقة أفضل، إلا أنهن يضحين مقابل ذلك بأجور أعلى. أما الأطفال، فيبدو أن لهم أثر محدود على أجور الساعة أو ساعات العمل بالنسبة للنساء. أما بالنسبة للنساء اللو اتي يحتمل أنهن يفضلن القيام بأدو ار تقليدية مرتبطة بكونهن إناثاً، كما يفضلن أن تكون خيار ات الخروج المتاحة لهن محدودة، فقد بينت الدراسة أنهن ينزعن إلى الدخول في هذا النوع من العمل، ربما من أجل الحفاظ على هويتهن وهوية أزو اجهن المرتبطة بالفروق بين الجنسين. تبين كذلك أن النساء العاملات من منازلهن أكثر احتمالاً لأن يتوجهن نحو العمل لجزء من الوقت، مما يسمح لهن بالاحتفاظ بوظائف متعددة، وهي ظاهرة شائعة لدى النساء الفقير ات (غلدستين 2001؛ تثانت 1993؛ بينيريا ورولدون 1987) وبالقيام بواجباتهن المنزلية. من جهة أخرى، تبين الدراسة أن الرجال من ذوي المستويات التعليمية المتننية، أو المتزوجين، أو الذين لهم أطفال، ليسو ا أكثر احتمالاً للتوجه نحو العمل من المنزل، ولأن تفرض عليهم عقوبة أقل من حيث الأجور، و لأن يعلوا في ورديات أقصر من الرجال الذين لا يعملون من منازلهم. 
كذلك، بينت الورقة أن العاملين من منازلهم يشكلون مجموعة جزئية من القوة العاملة، والتي تعتبر فرص سوق العمل المتاحة لأفرادها نادرة أو مكلفة. أما النساء اللو اتي لهن أسر، وغير المتعلمات و المتقدمات في السن، فلا تتوفر لهن مرونة الوقت (النساء)، أو المهار ات والقدرة على الانتقال (العاملون الأكبر سناً) للعمل خارج المنزل. وبدلاً عن ذلك، يوفر العمل من المنزل أفضل شكل من أشكال عمل السوق، وهو الشكل الذي بسمح لهن بالانخر اط فيه في ظل القيود المفروضة عليهن (بينيريا ورولدون 1987).

أخيراً، تجدر الإثارة إلى أن التحليل في هذه الورقة محدود، وذلك بسبب عدم وجود تعريف يمكن تحديده كمياً، وبغياب بيانات قطرية جيدة بخصوص الدو افع ور اء الدخول في هذا القطاع و أنماط العمل فيه. و ولن يتسنى فهم انتشار العمل من المنازل وأسباب التوظيف فيه ونوعية الوظائف المتاحة ضمنه إلا بعد الاتفاق على تعريف لهذا العمل وقيام دو ائر الإحصاءات في البلدان المعنية باستخدام هذا التعريف من أجل توحيد الاستبيانات التي تحوي أسئلة تستهدف در اسة هذه القضايا.

إذا أخذنا بالدروس المستقاة من هذه الورقة، وأردنا تخفيض معدلات انتشار العمل من المنازل، فإنه من الضروري العمل على إز الة الحواجز التي تقف في سبيل العمل خارج الأسرة المعيشية. وبالنسبة للنساء الفقير ات اللو اتي يتحملن مسؤوليات منزلية جسيمة، فإن وسائل توفير الوقت - منل المياه الجارية، الكهرباء، وخدات رعاية الأطفال ذات الساعات المرنة (بالنسبة لبعض الأقطار) - قد تسهم في تخفيض الكلفة المترنبة على عمل هؤ لاء النساء خارج المنزل. إضافة إلى ذلك، فإن توفر وسائل نقل أكثر تكراراً وكفاءة وسلامة لتخفيض الوقت اللازم للسفر إلى مكان العمل، سوف يتيح للمعاقين مغادرة منازلهم، ويخفف مخاطر سفرهم بدون مر افقين، ويفتح خيار ات سوق العمل المتاحة للنساء و المتقدمين في السن. أخيراً، إذا كانت الزوجة العاملة تشكل بالفعل تهديداً لهوية الرجال، فإن التنشئة الاجتماعية في المدارس ومؤسسات المجتمع المحلي الر امية إلى كسر المهام التقليدية المرتبطة بالنوع الاجتماعي، قادرة على تخفيف وصمة العار اللاصقة بالمر أة 
قد تكون المعلومات أحد مفاتيح تحسين أجور العاملين من منازلهم. ومع أن هذه الدراسة لم تتمكن من تقديم شرح و اضح للأسباب الكامنة ور اء حصول العاملين من منازلهم (وخاصة النساء) على أجور ساعية تقل عن أجور الساعة التي يحصل عليها نظر اؤهن في أماكن العمل في القطاع الرسمي، إلا أنه يجوز لنا أن نفترض أن ذلك يعود إلى المشاركة في سوق عمل تحتكره أقلية من أصحاب العمل الذين يشترون خدمات العاملين من منازلهم. بيد أن إخضاع العاملين من منازلهم لتنظيمات جماعية سيؤدي إلى تبادل المعلومات حول الرواتب (وظروف العمل) في السوق برمته، مما يرفع حدة المنافسة في السوق. أما على المدى البعيد، وفي الوقت الذي يجري فيه العمل على تخفيف القيود المفروضة على العمل خارج الأسرة المعيشية، فإن العاملين من منازلهم قد لا يدخلون السوق التنافسي بكل قو اهم، بل يكتفون فقط بالعمل في منازلهم إذا كانت أجور ومز ايا العمل من المنزل مفضلة على العمل خارج المنزل. 
الجداول

الجدول 1: نسبة أفراد القوة العاملة المنخرطين في العمل المنزلي

\begin{tabular}{|c|c|c|c|}
\hline سنة إعلان تحرير التجارة & سنة التقدير & النسبة المقدرة & \\
\hline 1991 & 1989 & 3.3 & الجز ائر 1 \\
\hline 1964 & 1989 & 2.9 & استر اليا1 \\
\hline 1991 & 1999 & 5.5 & البر ازيل2 \\
\hline 1991 & 1999 & 17.3 & الإكو ادور 2 \\
\hline 1994 & 1981 & 2.5 & الهند \\
\hline 1964 & 1988 & 1.6 & اليابان 1 \\
\hline 1986 & 1999 & 4.4 & المكسيك2 \\
\hline 1988 & $1980 \mathrm{~s}$ & 23.0 & الفلبين 1 \\
\hline 1991 & 1987 & 10.5 & بيرو \\
\hline منتصف القرن العشرين & 1981 & 2.3 & المملكة المتحدة1 \\
\hline منتصف القرن العشرين & 1985 & 7.53 & الو لايات المتحدة1 \\
\hline
\end{tabular}

1) منظمة العمل الدولية (1995)؛ 2) تقديرات المؤلفين. 
الجدول 2: انتشار العمل من المنزل، حسب فئة العمل من المنزل والجنس (النوع الاجتماعي)

\begin{tabular}{|c|c|c|c|}
\hline \multicolumn{3}{|c|}{ العاملون من المنزل كنسبة من القوة العاملة في الفئة } & \multirow[t]{2}{*}{ البرازيل } \\
\hline المجموع & إناث & ذكور & \\
\hline 3.6 & 6.3 & 1.6 & عاملون لحساب أنفسهم في القطاع غير \\
\hline 0.4 & 0.5 & 0.2 & مهنيون \\
\hline 0.04 & 0.08 & 0.01 & عاملون بعقود \\
\hline 0.4 & 0.7 & 0.2 & عاملون بدون أجر \\
\hline 1.2 & 2.4 & 0.3 & غير ذلك * \\
\hline \multirow[t]{2}{*}{5.5} & 9.9 & 2.3 & الجميع \\
\hline & & & الإكو ادور \\
\hline 7.4 & 12.8 & 3.4 & عاملون لحساب أنفسهم في القطاع غير \\
\hline 2.8 & 3.7 & 2.05 & مهنيون \\
\hline 0.2 & 0.3 & 0.1 & عاملون بعقود \\
\hline 4.0 & 5.9 & 2.5 & عاملون بدون أجر \\
\hline 2.9 & 4.8 & 1.4 & غير ذلك * \\
\hline \multirow[t]{2}{*}{17.3} & 27.6 & 9.5 & الجميع \\
\hline & & & المكسيك \\
\hline 3.2 & 5.5 & 1.8 & عاملون لحساب أنفسهم في القطاع غير \\
\hline 0.5 & 0.5 & 0.5 & مهنيون \\
\hline 0.07 & 0.08 & 0.06 & عاملون بعقود \\
\hline 0.5 & 1.0 & 0.2 & عاملون بدون أجر \\
\hline 0.2 & 0.3 & 0.08 & غير ذلك * \\
\hline 4.4 & 7.4 & 2.6 & الجميع \\
\hline
\end{tabular}

* أصحاب شركات، عمال خدمات، وعمال زر اعة. 
الجدول 3-أ: خصائص العاملين من المنزل في البرازيل (1999)، نسبة مئوية

\begin{tabular}{|c|c|c|c|}
\hline \multirow[b]{2}{*}{ بقية الاقتصاد * } & \multicolumn{2}{|c|}{ العاملون من المنزل } & \\
\hline & عقود & أصحاب مشاريع في & \\
\hline 57811 & 60 & 4851 & حجم العبنة \\
\hline 39.6 & 81.7 & 74.7 & إناث \\
\hline 31.06 & 20.0 & 11.6 & العمر 15-25 سنة \\
\hline 49.4 & 63.3 & 52.4 & العمر 26-45 سنة \\
\hline 19.5 & 16.7 & 36.08 & العمر 45+ سنة \\
\hline 11.5 & 11.4 & 14.6 & لم يلتحق بالمدارس \\
\hline 58.2 & 82.9 & 57.3 & تعليم ابتدائي \\
\hline 30.3 & 5.7 & 28.09 & تعليم ثانوي \\
\hline 49.4 & 16.7 & 41.3 & 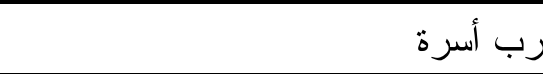 \\
\hline 37.5 & 3.3 & 17.8 & زوج \\
\hline 19.6 & 60.0 & 49.7 & زوجة \\
\hline 10.7 & 10.0 & 16.6 & أم غير متزوجة \\
\hline 2.8 & 5.0 & 5.09 & أنثى غير متزوجة، بدون أطفال \\
\hline 5.3 & 3.3 & 3.5 & ذكر غير متزوج \\
\hline 25.8 & 28.3 & 22.2 & طفل عمره 0-5 سنو ات مقيم في المنزل \\
\hline 33.3 & 38.3 & 34.6 & طفل عمره 6-12 سنة مقيم في المنزل \\
\hline 39.2 & 41.7 & 39.1 & طفل عمره 13-18 سنة مقيم في المنزل \\
\hline 50.01 & 43.3 & 50.2 & غير أبيض (ملون)** \\
\hline 63.0 & 42.0 & 52.0 & \% لهذا الدخل في دخل الأسرة؟ \\
\hline
\end{tabular}

* بقية الاقتصاد تعني العاملين، ولكن ليس من منازلهم.

العاملون لحساب أنفسهم حسب ما إذا كانو ا من الجنس الأسود (preto) أو من أجناس مختلطة (pardo). 
الجدول 3-ب: خصائص العاملين من المنزل في الإكو ادور (1999)، نسبة مئوية

\begin{tabular}{|c|c|c|c|}
\hline \multirow[b]{2}{*}{ بقية الاقتصاد * } & \multicolumn{2}{|c|}{ العاملون من المنزل } & \\
\hline & عقود & القطاع غير مشاريع في & \\
\hline 2228 & 13 & 464 & مجم العبينة \\
\hline 34.9 & 61.5 & 74.1 & إناث \\
\hline 29.5 & 38.5 & 7.1 & العمر 15-25 سنة \\
\hline 47.6 & 15.4 & 50.2 & العمر 26-45 سنة \\
\hline 22.9 & 46.2 & 42.7 & العمر 45+ سنة \\
\hline 3.3 & 0.0 & 3.9 & لم لميتحق بالمدارس \\
\hline 38.9 & 53.9 & 44.3 & تعليم ابتدائي \\
\hline 57.8 & 46.2 & 51.8 & تعليم ثانوي \\
\hline 47.0 & 23.1 & 42.5 & رب أسرة \\
\hline 25.9 & 15.4 & 15.3 & 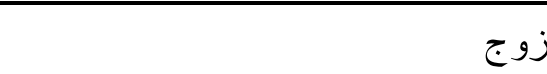 \\
\hline 13.2 & 23.1 & 31.7 & زوجة \\
\hline 12.7 & 15.4 & 22.6 & أم غير متزوجة \\
\hline 0.2 & 0.0 & 0.4 & أنثى غير متزوجة، بدون أطفال \\
\hline 21.7 & 23.1 & 4.7 & ذكر غير متزوج \\
\hline 30.1 & 30.8 & 25.4 & طفل عمره 0-5 سنو ات مقيم في المنزل \\
\hline 39.01 & 15.4 & 35.8 & طفل عمره 6-12 سنة مقيم في المنزل \\
\hline 38.9 & 76.9 & 40.1 & طفل عمره 13-18 سنة مقيم في المنزل \\
\hline N/A & N/A & N/A & غير أبيض (ملون)** \\
\hline 56.0 & 35.0 & 51.0 & \% لهذا الدخل في دخل الأسرة؟ \\
\hline
\end{tabular}

* بقية الاقتصاد تعني العاملين، ولكن ليس من منازلهم.




الجدول 3-ج: خصائص العاملين من المنزل في المكسيك (1999)، نسبة مئوية

\begin{tabular}{|c|c|c|c|}
\hline \multirow[b]{2}{*}{ بقية الاقتصاد } & \multicolumn{2}{|c|}{ العاملون من المنزل } & \\
\hline & عقود & |أصحاب مشاريع في & \\
\hline 89683 & 93 & 4322 & إناث \\
\hline 35.5 & 41.9 & 64.8 & العمر 15-25 سنة \\
\hline 31.7 & 48.4 & 8.5 & العمر 26-45 سنة \\
\hline 48.6 & 40.9 & 51.6 & العمر 45+ سنة \\
\hline 19.6 & 10.8 & 39.9 & لم يلتحق بالمدارس \\
\hline 5.05 & 11.0 & 13.05 & تعليم ابتدائي \\
\hline 73.5 & 75.3 & 71.7 & تعليم ثانوي \\
\hline 21.4 & 13.7 & 15.2 & رب أسرة \\
\hline 47.5 & 20.4 & 46.3 & زوج \\
\hline 37.3 & 14.0 & 23.7 & زوجة \\
\hline 13.8 & 20.4 & 35.5 & أم غير منزوجة \\
\hline 3.01 & 2.2 & 3.6 & أنثى غير متزوجة، بدون أطفال \\
\hline 11.0 & 12.9 & 5.04 & ذكر غير متزوج \\
\hline 19.0 & 34.4 & 5.8 & طفل عمره 0-5 سنو ات مقيم في المنزل \\
\hline 29.4 & 37.6 & 27.8 & طفل عمره 6-12 سنة مقيم في المنزل \\
\hline 40.03 & 62.4 & 41.4 & طفل عمه 13-18 سنة مقيم في المنزل \\
\hline 43.02 & 59.1 & 42.2 & غير أبيض (ملون)** \\
\hline N/A & N/A & N/A & \% لهذا الدخل في دخل الأسرة؛ \\
\hline 54.0 & 28.0 & 47.0 & حجم العينة \\
\hline
\end{tabular}

* بقية الاقتصاد تعني العاملين، ولكن ليس من منازلهم. الإثنية لم ترد في المسح. 
الجدول 4-أ: خصائص الثركات في البرازيل (1999)، نسبة مئوية

\begin{tabular}{|c|c|c|c|}
\hline \multirow[t]{2}{*}{ بقية الاقتصاد* } & \multicolumn{2}{|c|}{ عاملون من للمنزل } & \\
\hline & عقود & أصحاب مشاريع في الرسي & \\
\hline 57811 & 60 & 4851 & حجم العينة \\
\hline 58.4 & 6.7 & 0.0 & صاحب عمل في القطاع الرسمي(") \\
\hline 29.4 & 45.0 & 100.0 & حجم الثركة 0-5 \\
\hline 14.2 & 11.7 & 0.0 & حجم الثركة 6-10 \\
\hline 56.4 & 43.3 & 0.0 & حجم الشركة 11+ \\
\hline 29.4 & 51.7 & 40.3 & 1-1 أجر أدنى \\
\hline 50.6 & 44.8 & 43.8 & 1-3 أجر أدنى \\
\hline 11.3 & 1.7 & 9.1 & 3-5 أجر أدنى \\
\hline 6.5 & 1.7 & 5.0 & 5-10 أجر أدنى \\
\hline 2.3 & 0.0 & 1.8 & 10+ أجر أدنى \\
\hline 37.0 & 36.3 & 35.4 & عدد الساعات المعمولة الأسبوع \\
\hline 13.9 & 100.0 & 16.3 & التصنيع \\
\hline 18.3 & 0.0 & 14.6 &  \\
\hline 28.2 & 0.0 & 63.6 & الخذمات \\
\hline 8.6 & 0.0 & 0.0 & الزر اعة \\
\hline 30.9 & 0.0 & 5.5 & غير ذلك \\
\hline
\end{tabular}

* بقية الاقتصاد تعني العاملين، ولكن ليس من منازلهم. (أ) يعرف صاحب العمل في القطاع الرسمي على أنه العامل الذي يحمل بطاقة عمل موقعة من صاحب لهن العمل عند قيامه بتوظيف هذا العامل. 
الثكل 4-ب: خصائص الثركات في الإكوادور، نسبة مئوية

\begin{tabular}{|c|c|c|c|}
\hline بقية الاقتصاد* & & عاملون من للمنزل & \\
\hline & عقود & أصحاب مشاريع في القطاع غير الرسدي & \\
\hline 2228 & 13 & 464 & حجم العبنة \\
\hline 31.7 & 7.7 & 0.0 & صاحب عمل في القطاع الرسمي (أ) \\
\hline 60.4 & 69.2 & 100.0 & حجم الثركة 0-5 \\
\hline 8.0 & 0.0 & 0.0 & حجم الثركة 6-10 \\
\hline 31.6 & 30.8 & 0.0 & حجم الثركة 11+ \\
\hline 49.9 & 84.6 & 67.1 & 1-1 أجر أدنى \\
\hline 38.1 & 15.4 & 25.6 & 1-3 أجر أدنى \\
\hline 6.7 & 0.0 & 3.8 & 3-5 أجر أدنى \\
\hline 3.5 & 0.0 & 2.9 & 5-10 أجر أدنى \\
\hline 1.8 & 0.0 & 0.7 & 10+ أجر أدنى \\
\hline 43.3 & 31.4 & 32.3 & عدد الساعات المعمولة في الأسبوع \\
\hline 14.4 & 100.0 & 37.7 & التصنيع \\
\hline 28.7 & 0.0 & 36.2 & 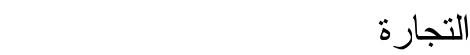 \\
\hline 38.5 & 0.0 & 25.2 & 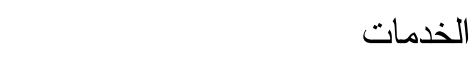 \\
\hline 7.6 & 0.0 & 0.9 & 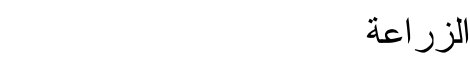 \\
\hline 10.8 & 0.0 & 0.0 & غلر ذلك \\
\hline
\end{tabular}

* بقية الاقتصاد تعني العاملين، ولكن ليس من منازلهم. (أ) يعرف صاحب العمل في القطاع الرسمي من خلال الإجابة ب "نعم" على السؤ ال فيما إذا كان العامل لديه




الثكل 4-ج: خصائص الشركات في المكسيك نسبة مئوية

\begin{tabular}{|c|c|c|c|}
\hline \multirow[t]{2}{*}{ بقية } & \multicolumn{2}{|r|}{ عاملون من للمنزل } & \\
\hline & عقود & أصداب مشاريع في القطاع غير & \\
\hline 89683 & 93 & 4322 & حجم العينة \\
\hline 54.9 & 19.7 & 0.0 & صاحب عمل في القطاع الرسمي \\
\hline 44.4 & 80.7 & 100.0 & حجم الشركة 0-5 \\
\hline 9.7 & 12.9 & 0.0 & حجم الشركة 6-15 \\
\hline 46.0 & 6.5 & 0.0 & حجم الثركة 16+ \\
\hline 9.3 & 17.5 & 19.4 & 0-1 أجر أدنى \\
\hline 49.0 & 62.5 & 51.2 & 1-3 أجر أدنى \\
\hline 20.4 & 15.0 & 16.9 & 3-5 أجر أدنى \\
\hline 14.9 & 4.2 & 9.0 & 5-10 أجر أدنى \\
\hline 6.5 & 0.8 & 3.5 & 10+ أجر أدنى \\
\hline 45.9 & 36.2 & 34.8 & 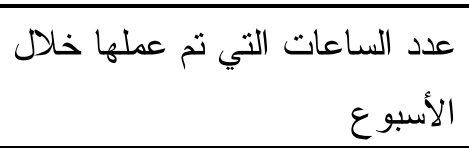 \\
\hline 22.9 & 100.0 & 43.0 & التصنيع \\
\hline 21.7 & 0.0 & 21.7 & التجارة \\
\hline 32.0 & 0.0 & 23.4 & الخدمات \\
\hline 1.7 & 0.0 & 0.0 & الزر اعة \\
\hline 21.8 & 0.0 & 11.9 & غير ذلك \\
\hline
\end{tabular}

* بقية الاقتصاد تعني العاملين، ولكن ليس من منازلهم.

* * *عرف صاحب العمل في القطاع الرسمي من خلال تمتعه بالمز ايا وكون حجم الثركة أكثر من خمسة عمال. 
الجدول 5-أ: البرازيل - احتمالات العمل من المنزل (بالنسبة للعمل خارج المنزل)*

\begin{tabular}{|c|c|c|c|}
\hline 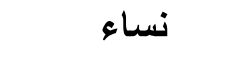 & 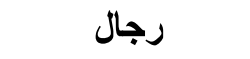 & 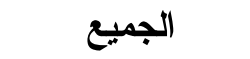 & \\
\hline & & $0.81(34.23)$ & | إناث \\
\hline$-0.83(-19.7)$ & $-0.43(-4.7)$ & $-0.74(-22.13)$ & العدر 15-25 \\
\hline$-0.39(-11.13)$ & $-0.25(-5.65)$ & $-0.36(-13.31)$ & العدر 26-45 \\
\hline $0.018(0.43)$ & $0.12(2.51)$ & $-0.12(-4.43)$ & رب أسرة \\
\hline $0.22(5.45)$ & $-0.13(-3.09)$ & $0.041(1.61)$ & |متزوج \\
\hline $0.1(3.25)$ & $-0.12(-2.79)$ & $0.014(0.57)$ & في الأسرة أطفال من عمر 5 سنو ات أو أقل \\
\hline $0.058(2.06)$ & $-0.061(-1.72)$ & $0.011(0.52)$ & في الأسرة أطفال من عد 6-12 سنة \\
\hline $0.028(1.06)$ & $-0.017(-0.49)$ & $0.0078(0.38)$ & في الأسرة أطفال من عدر 13-18 سنة \\
\hline$-0.051(-1.76)$ & $-0.018(-0.43)$ & $-0.08(-3.49)$ & في الأسرة بالغون غير متزوجون \\
\hline $0.048(1.96)$ & $0.0046(0.15)$ & $0.029(1.54)$ & | ملون (غير أبيض) \\
\hline $0.56(11.72)$ & $0.039(0.74)$ & $0.36(10.33)$ & لم يلتحق بالمدارس أبدا \\
\hline $0.37(14.16)$ & $-0.036(-1.04)$ & $0.25(11.62)$ & أنهى ما لو يزيب على 6 سنوات در/سة \\
\hline$-1.22(-21.05)$ & $-1.63(-20.78)$ & $-1.75(-33.55)$ & ثابت \\
\hline 0.066 & 0.023 & 0.12 & Pseudo R2 \\
\hline 19,687 & 33,035 & 52,722 & حجم العينة \\
\hline
\end{tabular}




الجدول 5-ب: الإكوادور - احتمالات العمل من المنزل (بالنسبة للعمل خارج المنزل)*

\begin{tabular}{|c|c|c|c|}
\hline نساء & رجال & الجميع & \\
\hline & & $\begin{array}{r}0.96 \\
(12.75)\end{array}$ & إناث \\
\hline $\begin{array}{r}-1.28 \\
(-8.13) \\
\end{array}$ & $\begin{array}{l}-0.086 \\
(-4.48) \\
\end{array}$ & $\begin{array}{r}-1.1 \\
(-9.32) \\
\end{array}$ & العدر 15-25 العد \\
\hline $\begin{array}{r}-0.43 \\
(-3.83) \\
\end{array}$ & $\begin{array}{r}-0.061 \\
(-3.8) \\
\end{array}$ & $\begin{array}{r}-0.44 \\
(-5.49) \\
\end{array}$ & العدر 26-45 \\
\hline $\begin{array}{r}0.1 \\
(0.09) \\
\end{array}$ & $\begin{array}{r}0.012 \\
(0.72) \\
\end{array}$ & $\begin{array}{l}0.0011 \\
(0.01)\end{array}$ &  \\
\hline $\begin{array}{r}0.074 \\
(0.75) \\
\end{array}$ & $\begin{array}{r}0.017 \\
(1.16) \\
\end{array}$ & $\begin{array}{r}0.11 \\
(1.68) \\
\end{array}$ & متزوج \\
\hline $\begin{array}{r}0.17 \\
(1.71) \\
\end{array}$ & $\begin{array}{r}-0.0047 \\
(-0.3) \\
\end{array}$ & $\begin{array}{r}0.08 \\
(1.05) \\
\end{array}$ & في الأسرة أطفال من عمر 5 سنوات أو أقل \\
\hline $\begin{array}{r}-0.12 \\
(-1.32) \\
\end{array}$ & $\begin{array}{l}-0.035 \\
(-2.51)\end{array}$ & $\begin{array}{r}-0.18 \\
(-2.59) \\
\end{array}$ & في الأسرة أطفال من عم 6-12 سنة \\
\hline $\begin{array}{l}0.24 \\
(2.7) \\
\end{array}$ & $\begin{array}{r}0.011 \\
(0.8) \\
\end{array}$ & $\begin{array}{r}0.18 \\
(2.74) \\
\end{array}$ & في الأسرة أطفال من عدر 13-18 سنة \\
\hline $\begin{array}{r}0.36 \\
(1.84) \\
\end{array}$ & $\begin{array}{r}0.035 \\
(1.7) \\
\end{array}$ & $\begin{array}{r}0.31 \\
(2.24) \\
\end{array}$ & في الأسرة بالغون غبر متزوجين \\
\hline $\begin{array}{r}-0.28 \\
(-1.35) \\
\end{array}$ & $\begin{array}{l}-0.056 \\
(-1.56) \\
\end{array}$ & $\begin{array}{r}-0.36 \\
(-1.98) \\
\end{array}$ & لم يلتحق بالمدارس أبدا \\
\hline $\begin{array}{r}-0.26 \\
(-0.29) \\
\end{array}$ & $\begin{array}{r}0.007 \\
(0.5) \\
\end{array}$ & $\begin{array}{r}0.043 \\
(0.64) \\
\end{array}$ & أنهى ما لا يزيب على 6 سنوات دراسة \\
\hline $\begin{array}{r}-0.47 \\
(-2.21) \\
\end{array}$ & $\begin{array}{r}-1.36 \\
(-5.53) \\
\end{array}$ & $\begin{array}{r}-1.34 \\
(-7.96) \\
\end{array}$ & ثابت \\
\hline 0.079 & 0.0813 & 0.17 & Pseudo R2 \\
\hline 1067 & 1638 & 2705 & حجم العينة \\
\hline
\end{tabular}

* قيم zاخل القوسين 
الجدول 5-ج: المكسيك - احتمالات العمل من المنزل (بالنسبة للعمل خارج المنزل)*

\begin{tabular}{|c|c|c|c|}
\hline نساء & رجال & الجميع & \\
\hline & & $\begin{array}{c}0.044 \\
(27.72)\end{array}$ & إناث \\
\hline $\begin{array}{c}-0.071 \\
(-19.46)\end{array}$ & $\begin{array}{c}-0.024 \\
(-12.49)\end{array}$ & $\begin{array}{c}-0.042 \\
(-25.77)\end{array}$ & العمر 15-25 الم \\
\hline $\begin{array}{c}-0.040 \\
(-12.15)\end{array}$ & $\begin{array}{l}-0.012 \\
(-7.4)\end{array}$ & $\begin{array}{c}-0.023 \\
(-15.92)\end{array}$ & العمر 26-45 \\
\hline $\begin{array}{l}0.007 \\
(1.82)\end{array}$ & $\begin{array}{l}0.007 \\
(3.57)\end{array}$ & $\begin{array}{l}-0.007 \\
(-4.9)\end{array}$ &  \\
\hline $\begin{array}{c}0.036 \\
(10.02)\end{array}$ & $\begin{array}{l}-0.008 \\
(-5.49)\end{array}$ & $\begin{array}{l}0.005 \\
(3.97)\end{array}$ & متزوج \\
\hline $\begin{array}{l}0.017 \\
(4.41)\end{array}$ & $\begin{array}{l}-0.002 \\
(-1.58)\end{array}$ & $\begin{array}{l}0.004 \\
(3.00)\end{array}$ & في الأسرة أطفال من عمر 5 سنوات أو أقل \\
\hline $\begin{array}{l}0.006 \\
(2.24)\end{array}$ & $\begin{array}{l}-0.001 \\
(-1.00)\end{array}$ & $\begin{array}{l}0.002 \\
(1.21)\end{array}$ & في الأسرة أطفال من عمر 6-12 سنة \\
\hline $\begin{array}{l}-0.005 \\
(-1.78)\end{array}$ & $\begin{array}{l}0.001 \\
(1.29)\end{array}$ & $\begin{array}{l}-0.000 \\
(-0.08)\end{array}$ & في الأسرة أطفال من عمر 13-18 سنة \\
\hline $\begin{array}{l}-0.002 \\
(-0.69) \\
\end{array}$ & $\begin{array}{l}0.003 \\
(2.00) \\
\end{array}$ & $\begin{array}{l}-0.003 \\
(-2.22) \\
\end{array}$ & في الأسرة بالغون غير متزوجين \\
\hline $\begin{array}{c}0.095 \\
(13.28) \\
\end{array}$ & $\begin{array}{l}0.004 \\
(1.35) \\
\end{array}$ & $\begin{array}{c}0.04 \\
(12.28) \\
\end{array}$ & لم يلتحق بالمدارس أبداً \\
\hline $\begin{array}{c}0.033 \\
(10.41)\end{array}$ & $\begin{array}{l}0.003 \\
(2.09)\end{array}$ & $\begin{array}{c}0.014 \\
(10.99)\end{array}$ & أنهى ما لا يزيد على 6 سنو ات دراسة \\
\hline 0.0966 & 0.0308 & 0.0895 & Pseado $\mathrm{R}^{2}$ \\
\hline 33615 & 60483 & 94098 & حجم العينة \\
\hline
\end{tabular}

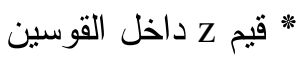


الجدول 6-أ: البرازيل - ساعات العمل المسجلة للقوة العاملة ككل ومع تصحيح هكمان *

\begin{tabular}{|c|c|c|c|c|c|c|}
\hline \multicolumn{3}{|c|}{ الأجر بعد تصحيح هكمان } & \multicolumn{3}{|c|}{ تقدير أجر الساعة } & \\
\hline نساء & رجال & الجميع & نساء & رجال & الجميع & \\
\hline & & & & & & الأجبيرون \\
\hline---- & --- & $\begin{array}{c}-0.11 \\
(-11.77)\end{array}$ & ---- & ---- & $\begin{array}{c}-0.26 \\
(-40.73)\end{array}$ & إناث \\
\hline $\begin{array}{c}-0.52 \\
(-31.85) \\
\end{array}$ & $\begin{array}{c}-0.61 \\
(-49.77) \\
\end{array}$ & $\begin{array}{c}-0.57 \\
(-58.55) \\
\end{array}$ & $\begin{array}{c}-0.51 \\
(-32.6) \\
\end{array}$ & $\begin{array}{c}-0.63 \\
(-52.34) \\
\end{array}$ & $\begin{array}{l}-0.59 \\
(-1.75) \\
\end{array}$ & العدر 15-25 \\
\hline $\begin{array}{c}-0.17 \\
(-10.42)\end{array}$ & $\begin{array}{c}-0.24 \\
(-20.03)\end{array}$ & $\begin{array}{c}-0.22 \\
(-22.89)\end{array}$ & $\begin{array}{c}-0.16 \\
(-11.13)\end{array}$ & $\begin{array}{c}-0.12 \\
(-10.9)\end{array}$ & $\begin{array}{c}-0.14 \\
(-15.74)\end{array}$ & العدر 26-45 \\
\hline $\begin{array}{c}-0.21 \\
(-22.11)\end{array}$ & $\begin{array}{c}-0.24 \\
(-32.56)\end{array}$ & $\begin{array}{c}-0.24 \\
(-39.77)\end{array}$ & $\begin{array}{c}-0.21 \\
(-22.07)\end{array}$ & $\begin{array}{c}-0.24 \\
(-32.68)\end{array}$ & $\begin{array}{c}-0.24 \\
(-39.64)\end{array}$ & ملون (غبير أبيض) \\
\hline $\begin{array}{c}-0.84 \\
(-25.45)\end{array}$ & $\begin{array}{c}-0.94 \\
(-64.84)\end{array}$ & $\begin{array}{c}-0.85 \\
(-64.95)\end{array}$ & $\begin{array}{c}-0.88 \\
(-40.01)\end{array}$ & $\begin{array}{c}-1.0 \\
(-72.19)\end{array}$ & $\begin{array}{c}-0.97 \\
(-83.01)\end{array}$ & لم بلتحق بددرسة أبدا \\
\hline $\begin{array}{c}-0.39 \\
(-25.37)\end{array}$ & $\begin{array}{c}-0.43 \\
(-49.04)\end{array}$ & $\begin{array}{c}-0.38 \\
(-53.21)\end{array}$ & $\begin{array}{c}-0.41 \\
(-41.63)\end{array}$ & $\begin{array}{c}-0.46 \\
(-54.23)\end{array}$ & $\begin{array}{c}-0.44 \\
(-68.67)\end{array}$ & ما لا بزيد على 6 سنوات در/سة \\
\hline $\begin{array}{c}-0.26 \\
(-17.18)\end{array}$ & $\begin{array}{c}-0.11 \\
(-4.49)\end{array}$ & $\begin{array}{c}-0.21 \\
(-16.39)\end{array}$ & $\begin{array}{c}-0.26 \\
(-17.31)\end{array}$ & $\begin{array}{c}-0.11 \\
(-4.61)\end{array}$ & $\begin{array}{c}-0.22 \\
(-17.23)\end{array}$ & يعل في منزله \\
\hline $\begin{array}{c}-2.75 \\
(-90.05)\end{array}$ & $\begin{array}{c}-2.3 \\
(-164.1)\end{array}$ & $\begin{array}{c}-2.39 \\
(-211.54)\end{array}$ & $\begin{array}{c}-2.8 \\
(-187.1)\end{array}$ & $\begin{array}{c}-2.49 \\
(-207.9)\end{array}$ & $\begin{array}{c}-2.51 \\
(-256.3)\end{array}$ & ثابت \\
\hline ---- & ---- & ---- & 0.19 & 0.25 & 57057 & $\mathrm{R} 2$ \\
\hline 58325 & 53223 & 111548 & 21055 & 36002 & 0.24 & حجم العينة \\
\hline
\end{tabular}

* قيم t وقيم z داخل القوسين 
الجدول 6-ب: الإكوادور - ساعات العمل المسجلة للقوة العاملة ككل ومع تصحيح هكمان *

\begin{tabular}{|c|c|c|c|c|c|c|}
\hline \multicolumn{3}{|c|}{ الأجر بعد تصحيح هكمان } & \multicolumn{3}{|c|}{ تقدير أجر الساعة } & \\
\hline الجميع & نساء & رجال & Women & Men & All & \\
\hline & & & & & & الأجبيرون \\
\hline---- & ---- & $\begin{array}{c}0.33 \\
(6.47)\end{array}$ & ---- & -- & $\begin{array}{l}-0.13 \\
(-3.55)\end{array}$ & إباث \\
\hline $\begin{array}{c}0.00071 \\
(0.01)\end{array}$ & $\begin{array}{c}-0.27 \\
(-4.04)\end{array}$ & $\begin{array}{c}-0.19 \\
(-3.18)\end{array}$ & $\begin{array}{c}-0.44 \\
(-4.46)\end{array}$ & $\begin{array}{l}-0.41 \\
(-7.0)\end{array}$ & $\begin{array}{l}-0.43 \\
(-8.27)\end{array}$ & العدر 19-25 \\
\hline $\begin{array}{l}-0.38 \\
(-3.8)\end{array}$ & $\begin{array}{l}-0.087 \\
(-1.52)\end{array}$ & $\begin{array}{c}-0.19 \\
(-3.74)\end{array}$ & $\begin{array}{l}-0.055 \\
(-0.71)\end{array}$ & $\begin{array}{r}0.0044 \\
(0.08)\end{array}$ & $\begin{array}{r}-0.031 \\
(-0.7)\end{array}$ & العدر 26-45 \\
\hline $\begin{array}{c}-0.64 \\
(-3.27) \\
\end{array}$ & $\begin{array}{c}-0.57 \\
(-3.49) \\
\end{array}$ & $\begin{array}{c}-0.54 \\
(-4.68) \\
\end{array}$ & $\begin{array}{c}-0.51 \\
(-3.37) \\
\end{array}$ & $\begin{array}{c}-0.7 \\
(-4.55) \\
\end{array}$ & $\begin{array}{c}-0.57 \\
(-5.48) \\
\end{array}$ & لم يلتحق بددرسة أبدا \\
\hline $\begin{array}{c}-0.37 \\
(-4.28)\end{array}$ & $\begin{array}{c}-0.22 \\
(-4.93)\end{array}$ & $\begin{array}{c}-0.28 \\
(-6.66)\end{array}$ & $\begin{array}{c}-0.28 \\
(-4.16)\end{array}$ & $\begin{array}{c}-0.2 \\
(-4.61)\end{array}$ & $\begin{array}{l}-0.23 \\
(-6.17)\end{array}$ & ما لا بزبي على 6 سنوات درسة \\
\hline $\begin{array}{l}-0.21 \\
(-3.41)\end{array}$ & $\begin{array}{r}-0.051 \\
(0.69)\end{array}$ & $\begin{array}{c}-0.2 \\
(-4.26)\end{array}$ & $\begin{array}{l}-0.41 \\
(-6.05)\end{array}$ & $\begin{array}{l}0.042 \\
(0.56)\end{array}$ & $\begin{array}{l}-0.26 \\
(-5.36)\end{array}$ & يعدل في منزله \\
\hline $\begin{array}{c}8.64 \\
(76.67)\end{array}$ & $\begin{array}{c}7.46 \\
(114.2)\end{array}$ & $\begin{array}{c}7.65 \\
(136.22)\end{array}$ & $\begin{array}{c}7.25 \\
(87.41)\end{array}$ & $\begin{array}{c}7.24 \\
(139.61)\end{array}$ & $\begin{array}{l}7.3 \\
(157)\end{array}$ & ثابت \\
\hline--- & ---- & ---- & 0.059 & 0.063 & 0.063 & $\mathrm{R} 2$ \\
\hline 2673 & 2163 & 4836 & 1024 & 1573 & 2597 & حجم العينة \\
\hline
\end{tabular}




الجدول 6-ج: المكسيك - ساعات العمل المسجلة للقوة العاملة ككل ومع تصحيح هكمان *

\begin{tabular}{|c|c|c|c|c|c|c|}
\hline \multicolumn{3}{|c|}{ الأجر بعد تصحيح هكمان } & \multicolumn{3}{|c|}{ تقدير أجر الساعة } & \\
\hline الجميع & نساء & رجال & Women & Men & All & \\
\hline & & & & & & الأجيرون \\
\hline---- & ---- & $\begin{array}{c}-0.16 \\
(-42.99)\end{array}$ & ---- & --- & $\begin{array}{c}-0.13 \\
(-32.0)\end{array}$ & إناث \\
\hline $\begin{array}{c}-0.47 \\
(-48.37)\end{array}$ & $\begin{array}{c}-0.48 \\
(-66.41)\end{array}$ & $\begin{array}{c}-0.47 \\
(-81.98)\end{array}$ & $\begin{array}{c}-0.37 \\
(-34.49)\end{array}$ & $\begin{array}{c}-0.33 \\
(-45.06)\end{array}$ & $\begin{array}{c}-0.35 \\
(-56.74)\end{array}$ & العدر 15-25 \\
\hline $\begin{array}{c}-0.1 \\
(-11.39) \\
\end{array}$ & $\begin{array}{c}-0.096 \\
(-14.85) \\
\end{array}$ & $\begin{array}{c}-0.098 \\
(-18.67) \\
\end{array}$ & $\begin{array}{l}-0.08 \\
(-8.0) \\
\end{array}$ & $\begin{array}{l}-0.031 \\
(-4.52) \\
\end{array}$ & $\begin{array}{l}-0.048 \\
(-8.53) \\
\end{array}$ & العدر 26-45 \\
\hline $\begin{array}{c}-1.13 \\
(-74.27)\end{array}$ & $\begin{array}{c}-1.03 \\
(-82.57)\end{array}$ & $\begin{array}{c}-1.07 \\
(-111.3)\end{array}$ & $\begin{array}{c}-0.87 \\
(-54.91)\end{array}$ & $\begin{array}{l}-0.67 \\
(-52.57)\end{array}$ & $\begin{array}{c}-0.76 \\
(-77.03)\end{array}$ & لم بلتحق بددرسة \\
\hline $\begin{array}{c}-0.65 \\
(-106.2)\end{array}$ & $\begin{array}{c}-0.61 \\
(-123.85)\end{array}$ & $\begin{array}{c}-0.63 \\
(-162.8)\end{array}$ & $\begin{array}{c}-0.42 \\
(-55.93)\end{array}$ & $\begin{array}{l}-0.29 \\
(-44.59)\end{array}$ & $\begin{array}{c}-0.35 \\
(-71.52)\end{array}$ & سا لا بزيد على 6 سرات 6 \\
\hline $\begin{array}{c}-0.29 \\
(-23.4)\end{array}$ & $\begin{array}{l}-0.074 \\
(-4.83)\end{array}$ & $\begin{array}{c}-0.21 \\
(-21.67)\end{array}$ & $\begin{array}{c}-0.27 \\
(-20.54)\end{array}$ & $\begin{array}{l}-0.038 \\
(-2.34)\end{array}$ & $\begin{array}{c}-0.19 \\
(-18.69)\end{array}$ & يعطل في منزله \\
\hline $\begin{array}{c}1.92 \\
(193.5)\end{array}$ & $\begin{array}{c}2.029 \\
(266.37)\end{array}$ & $\begin{array}{c}2.05 \\
(342.3)\end{array}$ & $\begin{array}{c}1.63 \\
(154.9)\end{array}$ & $\begin{array}{c}1.62 \\
(196.3)\end{array}$ & $\begin{array}{c}1.69 \\
(252.46)\end{array}$ & ثابت \\
\hline--- & --- & --- & 0.16 & 0.09 & 0.12 & $\mathrm{R} 2$ \\
\hline 58980 & 97662 & 156642 & 37283 & 67653 & 104936 & العبنة \\
\hline
\end{tabular}

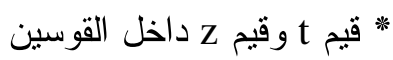


الجدول 7 - البرازيل - الساعات المعمولة (1999)*

\begin{tabular}{|c|c|c|c|}
\hline نساء & رجال & الجميع & \\
\hline & & $\begin{array}{c}-0.16 \\
(-42.91)\end{array}$ & إناث \\
\hline $\begin{array}{l}0.076 \\
(7.28)\end{array}$ & $\begin{array}{l}-0.010 \\
(-1.64)\end{array}$ & $\begin{array}{l}0.028 \\
(5.38)\end{array}$ & العدر 15-25 \\
\hline $\begin{array}{l}0.081 \\
(8.72) \\
\end{array}$ & $\begin{array}{l}0.023 \\
(4.81) \\
\end{array}$ & $\begin{array}{c}0.048 \\
(10.67) \\
\end{array}$ & العدر 26-45 \\
\hline $\begin{array}{c}0.057 \\
(5.5) \\
\end{array}$ & $\begin{array}{l}0.076 \\
(4.81) \\
\end{array}$ & $\begin{array}{c}0.092 \\
(22.34) \\
\end{array}$ & سرة \\
\hline $\begin{array}{l}-0.011 \\
(-1.11)\end{array}$ & $\begin{array}{l}0.020 \\
(4.38)\end{array}$ & $\begin{array}{l}0.019 \\
(4.88)\end{array}$ & متزوج \\
\hline $\begin{array}{l}-0.023 \\
(-2.66) \\
\end{array}$ & $\begin{array}{l}0.012 \\
(2.88)\end{array}$ & $\begin{array}{c}-0.001 \\
(-0.33) \\
\end{array}$ & في الأسرة أطفال 5 سنوات أو أقل \\
\hline $\begin{array}{l}-0.021 \\
(-2.78) \\
\end{array}$ & $\begin{array}{l}0.011 \\
(2.94)\end{array}$ & $\begin{array}{l}-0.002 \\
(-0.5)\end{array}$ & في الأسرة أطفال عمرهم 6-12 سنة \\
\hline $\begin{array}{l}0.001 \\
(0.16) \\
\end{array}$ & $\begin{array}{l}-0.018 \\
(-4.95) \\
\end{array}$ & $\begin{array}{l}-0.011 \\
(-3.33) \\
\end{array}$ & في الأسرة أطفال عمرهم 13-18 سنة \\
\hline $\begin{array}{l}0.032 \\
(4.19) \\
\end{array}$ & $\begin{array}{l}0.014 \\
(3.42) \\
\end{array}$ & $\begin{array}{r}0.026 \\
(6.82) \\
\end{array}$ & في الأسرة بالغون (غير متزوجين) \\
\hline $\begin{array}{l}-0.045 \\
(-7.13) \\
\end{array}$ & $\begin{array}{l}-0.007 \\
(-2.33 \\
\end{array}$ & $\begin{array}{l}-0.021 \\
(-7.09) \\
\end{array}$ & ملون (غير أبيض) \\
\hline $\begin{array}{c}-0.322 \\
(-34.84)\end{array}$ & $\begin{array}{l}-0.092 \\
(-9.16)\end{array}$ & $\begin{array}{c}-0.267 \\
(-42.45)\end{array}$ & يعمل في المنزل \\
\hline 0.063 & 0.022 & 0.10 & $\mathrm{R} 2$ \\
\hline 24105 & 45267 & 69372 & حجم العينة \\
\hline
\end{tabular}

* قيم t داخل القوسين 
الجدول 7ب - الإكوادور - الساعات المعمولة

\begin{tabular}{|c|c|c|c|}
\hline نساء & رجال & الجميع & \\
\hline ---- & ---- & $\begin{array}{r}-0.332 \\
(-10.1) \\
\end{array}$ & إناث \\
\hline $\begin{array}{l}0.334 \\
(3.52)\end{array}$ & $\begin{array}{l}0.140 \\
(2.95)\end{array}$ & $\begin{array}{l}0.213 \\
(4.67)\end{array}$ & العدر 15-25 \\
\hline $\begin{array}{r}0.109 \\
(1.47) \\
\end{array}$ & $\begin{array}{l}0.111 \\
(2.95) \\
\end{array}$ & $\begin{array}{c}0.104 \\
(2.87) \\
\end{array}$ & العدر 26-45 \\
\hline $\begin{array}{l}0.205 \\
(2.66) \\
\end{array}$ & $\begin{array}{l}0.128 \\
(3.12) \\
\end{array}$ & $\begin{array}{c}0.213 \\
(6.19) \\
\end{array}$ & سرة \\
\hline $\begin{array}{c}0.087 \\
(1.31)\end{array}$ & $\begin{array}{l}0.066 \\
(2.05)\end{array}$ & $\begin{array}{l}0.061 \\
(2.09)\end{array}$ & متزو \\
\hline $\begin{array}{c}-0.290 \\
(-4.3)\end{array}$ & $\begin{array}{l}0.078 \\
(2.32) \\
\end{array}$ & $\begin{array}{l}-0.064 \\
(-1.97) \\
\end{array}$ & في الأسرة أطفال 5 سنوات أو أقل \\
\hline $\begin{array}{l}-0.037 \\
(-0.59) \\
\end{array}$ & $\begin{array}{l}0.006 \\
(0.19) \\
\end{array}$ & $\begin{array}{c}-0.014 \\
(-0.48) \\
\end{array}$ & في الأسرة أطفال عمرهم 6-12 سنة \\
\hline $\begin{array}{l}-0.107 \\
(-1.76) \\
\end{array}$ & $\begin{array}{c}0.021 \\
(0.7) \\
\end{array}$ & $\begin{array}{l}-0.036 \\
(-1.24) \\
\end{array}$ & في الأسرة أطفال عمرهم 13-18 سنة \\
\hline $\begin{array}{c}0.064 \\
(0.5)\end{array}$ & $\begin{array}{l}-0.040 \\
(-0.75) \\
\end{array}$ & $\begin{array}{c}0.038 \\
(0.71) \\
\end{array}$ & في الأسرة بالغون (غير متزوجين) \\
\hline $\begin{array}{r}-0.461 \\
(-7.38) \\
\end{array}$ & $\begin{array}{r}-0.135 \\
(-2.57) \\
\end{array}$ & $\begin{array}{c}-0.364 \\
(-9.3) \\
\end{array}$ & 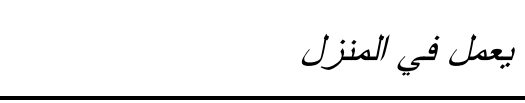 \\
\hline 0.091 & 0.0306 & 0.1453 & R2 \\
\hline 1050 & 1900 & 2950 & حجم العينة \\
\hline
\end{tabular}

* قيم t داخل القوسين 
الجدول 7ج - المكسيك - الساعات المعمولية

\begin{tabular}{|c|c|c|c|}
\hline نساء & رجال & الجميع & \\
\hline-- & ---- & $\begin{array}{c}-0.18 \\
(-61.03)\end{array}$ & إناث \\
\hline $\begin{array}{c}0.15 \\
(17.33) \\
\end{array}$ & $\begin{array}{c}0.03 \\
(7.11) \\
\end{array}$ & $\begin{array}{c}0.10 \\
(24.55) \\
\end{array}$ & $25-15 \gamma$ \\
\hline $\begin{array}{c}0.10 \\
(13.71) \\
\end{array}$ & $\begin{array}{c}0.05 \\
(16.11) \\
\end{array}$ & $\begin{array}{c}0.08 \\
(24.38) \\
\end{array}$ & $45-26 \mu$ \\
\hline $\begin{array}{c}0.02 \\
(2.26) \\
\end{array}$ & $\begin{array}{c}0.06 \\
(14.06) \\
\end{array}$ & $\begin{array}{c}0.11 \\
(32.9) \\
\end{array}$ & \\
\hline $\begin{array}{c}-0.1 \\
(-14.33) \\
\end{array}$ & $\begin{array}{c}0.02 \\
(7.71) \\
\end{array}$ & $\begin{array}{c}-0.01 \\
(-4.61) \\
\end{array}$ & متزوج \\
\hline $\begin{array}{c}-0.04 \\
(-6.08) \\
\end{array}$ & $\begin{array}{c}0.02 \\
(6.37) \\
\end{array}$ & $\begin{array}{c}-0.00 \\
(-1.22) \\
\end{array}$ & الأسرة أطفال 5 سنوات أو أقل \\
\hline $\begin{array}{c}-0.03 \\
(-5.04) \\
\end{array}$ & $\begin{array}{c}0.01 \\
(1.76) \\
\end{array}$ & $\begin{array}{c}-0.01 \\
(-2.40) \\
\end{array}$ & في الأسرة أطفال عمرهم 6-12 سنة \\
\hline $\begin{array}{l}-0.00 \\
(-0.1) \\
\end{array}$ & $\begin{array}{c}-0.01 \\
(-3.54) \\
\end{array}$ & $\begin{array}{c}-0.01 \\
(-2.74) \\
\end{array}$ & في الأسرة أطفال عمرهم 13-18 سنة \\
\hline $\begin{array}{l}0.05 \\
(8.8) \\
\end{array}$ & $\begin{array}{l}0.02 \\
(8.4) \\
\end{array}$ & $\begin{array}{c}0.05 \\
(19.43) \\
\end{array}$ & في الأسرة بالغون (غير متزوجين) \\
\hline $\begin{array}{c}-0.38 \\
(-40.6) \\
\end{array}$ & $\begin{array}{c}-0.18 \\
(-22.67) \\
\end{array}$ & $\begin{array}{c}-0.32 \\
(-55.65) \\
\end{array}$ & في - المنزل \\
\hline 0.086 & 0.026 & 0.12 & $\mathrm{R} 2$ \\
\hline 38324 & 70091 & 108415 & حجم العينة \\
\hline
\end{tabular}

* قيم t داخل القوسين 


\section{المراجع}

أكرلوف وكر انتون (Akerloff, George and Rachel Kranton). 1999. "الاقتصاد و الهوية ( Quarterly Journal of (Economics and Identity .753-715، (Economics

أرياغادا (Arriagada, Irma). 1998. سوق العقل النسائي في الدناطق الحضرية في أمبيركا اللاتينية: The Urban Female Labour Market in Latin America: The Myth ) الخر افة والحقيقة (and the Reality بينيـريا ورولــدون (Beneria, Lourdes and Martha Roldon). 1987. تجاوزات الطبقة الاجتماعية و الـنوع الاجنماعـي (Las Encrucijadas de Clase y Género). منشورات جامعة شيكاغو، الولايات المتحدة.

de Ferranti, David, Guillermo E. Perry, Daniel ) دي فير انتي، غييرمو، ليدرمان ومالوني 2002. 2002. من الموارد الطبيعية إلى اقتصاد المعرفة:

From Natural Resources to the Knowledge Economy: ) التجارة وجودة الوظيفة (Trade and Job Quality

كار ، تشين وتيت (Carr, Marilyn, Martha Chen, and Jane Tate). 2000. "العولمة و العاملون من

منازلهم" ("Globalization and Home-Based Workers") ). في: اقتصاديات المرأة ( Feminist Economics

Whant, Sylvia) تشانت 1991. النساء و البقاء في المدن المكسيكية ( Women and Survival in)

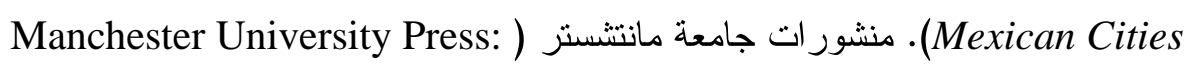
.(Manchester

تشين، سبستاد و اوكونول (Chen, Martha, Jenifer Sebstad, and Leslie O’Connell). 1999. "إحصاء القوة العاملة غير المنظورة: حالة العاملين من منازلهم ( Counting the Invisible" World (Workforce: The Case of Homebased Workers" (Development

كننغهام ومالوني (Cunningham, Wendy and William Maloney). 2001. "التباين في قطاع المؤسسات البالغة الصغر في المكسيك: تطبيق: نطبيق لتحليل العو امل و المجموعات" (

"Heterogeneity in the Mexican Micro-Enterprise Sector: An Application of

Economic (Factor and Cluster Analysis”  
غلدستين (Geldstein, Rosa). 2000. "استر اتيجيات التغلب على المشكلات الخارجة عن سوق العمل في الأرجنتين" ("Non-Labor Market Coping Strategies in Argentina") ). منشور عندئ

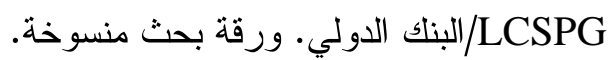

غونز الس دي رونتا (Gonzalez de Rocha, Mercedes). 1994. موارد الفقر: النساء والبقاء في مدينة مكسيكية (The Resources of Poverty: Women and Survival in a Mexican City). منشور ات بلاكويل: ماساتثوستس (Blackwell Publishers: Massachusetts) .

جيلين، ميركادو ، وويزيكير (Jelin, Elizabeth, Matilde Mercado and Gabriela Wyczykier). 2000. "العمل المنزلي في الأرجنتين" ("Home Work in Argentina") ). ورقة عمل رقم 6 Working Paper حول العاملين من منازلهم في الاقتصاد العالمي SEED فلسلة در اسات 60ries on Homeworkers in the Global Economy مالوني (Maloney, William). قيد النشر · "إعادة زيارة اللارسمية" (”Informality Revisited") في: التتمية الدولية (World Development). . .

بروغل وتتكر (Prugl, Elisabeth and Irene Tinker). 1997. "أصحاب المشاريع البالغة الصغر

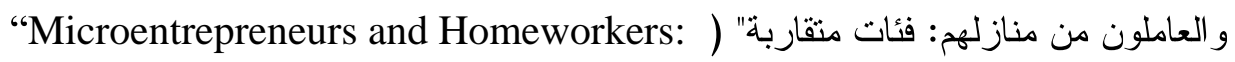

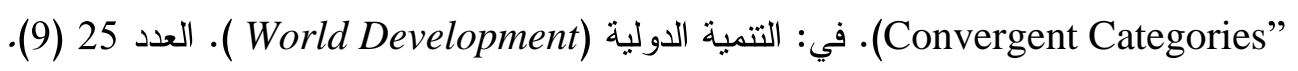

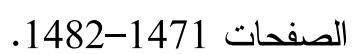

تومي (Tomei, Manuela).

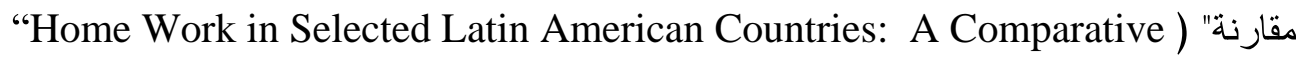
(Overview”). غير منشور . منظمة العمل الدولية: جنيف).

WIEGO (Women in Informal ) شبكة ويغو (النساء و الوظائف في القطاع غير الرسمي) وانو .wWw.wiego.org ·(Women in the Informal Economy)

وودون (Wodon, Quentin). 2000. الفقر والسياسات في دنطقة أمبركا اللاتينية والبحر الكاريبي. ورقة تقنية للبنك الدولي، رقم 467. البنك الدولي: و اشنطن، دي سي ولئ 